\title{
COST-SHARING STRATEGY FOR RECYCLING AND SERVICE INVESTMENT IN A CLOSED-LOOP SUPPLY CHAIN
}

\author{
Renbang Shan*๑, Li Luo and Ran Kou
}

\begin{abstract}
This paper investigates the cost-sharing strategies of a manufacturer, a retailer and a thirdparty recycler in a Stackelberg game considering government subsidy and retailer's service effort. Next, we construct profit functions of the manufacturer, the retailer and the third-party recycler considering government subsidy and service effort for four scenarios: no cost-sharing (N), service investment costsharing (I), recycling investment cost-sharing (II), and both service and recycling investment costsharing (III). Furthermore, we obtain the optimal results and discuss the impact of cost-sharing ratio, service cost coefficient, government subsidy and service sensitivity coefficient on profits and social net benefits. The results show that the service investment cost-sharing strategy cannot achieve profit coordination, and under certain conditions, the recycling investment cost-sharing strategy and the service and recycling investment cost-sharing strategy can achieve profit coordination. In addition, changes in different factors such as government subsidy, service cost coefficients, and service sensitivity coefficients will affect the effectiveness of cost-sharing strategies.
\end{abstract}

Mathematics Subject Classification. 91A80.

Received May 13, 2021. Accepted September 16, 2021.

\section{INTRODUCTION}

With the continuous development of social economy, people's attitude towards products has gradually changed from only focusing on the use value of the product to focusing on the use value and added value of the product at the same time. Now, the market demand is no longer only affected by price, but also by other additional factors (such as product pre-sale service, in-sale service and after-sales service, etc.). In the electronics market, the iterative speed of electronic products is much faster, which increases the product categories and leads to more intense products competition. In order to better attract the consumers, most brands have set up physical experience stores to stimulate the demand through consumer experience. In the field of digital products and fashion, the service has gone beyond the price and becomes the most important factor affecting whether goods are purchased. For example, when consumers purchase computers, printers or other digital products, they often pay attention to the after-sales service (such as maintenance, unconditional refund, and return, etc.) [14,48]. The Dell (DELL) provides customized computer services for customers. Thus, the customers can enjoy the liberty to select and assemble various customized models of computers. Another example is that UNIQLO provides

Keywords. Closed-loop supply chain, government subsidy, service effort, cost-sharing.

Business School of Sichuan University, Chengdu 610065, P.R. China.

*Corresponding author: rbshan0528@163.com 
customers with an intelligent shopping guide ${ }^{1}$ Therefore, as people pay more and more attentions to the various services in the process of shopping, people's shopping habit is changing from purchasing goods to purchasing services and experiences. Improving the quality of life and gaining experience have gradually become the core motivation of consumers, providing or innovating service is an important way for enterprises to seize the market and achieve high profits.

At the same time, with the change of consumption patterns, the iterative speed of product has accelerated, resulting in more and more waste products, which brings about resource occupation and environmental problems. Therefore, people have to take measures to solve these problems. As early as the beginning of the 21st century, the European Union issued relevant policies (restrictions) to encourage enterprises to participate in the recycling and remanufacturing. Subsequently, the No. 22 document issued by China clearly stated that the government will support the recycling and remanufacturing of waste products ${ }^{2}$. In 2011, the Ministry of Finance set up the waste electrical and electronic equipment disposal Fund (WEEE) to finance the recycling and remanufacturing of waste electrical and electronic products [51]. The Japan and Germany have begun to issue relevant policies and regulations to regulate enterprises and improve the utilization rate of resources. According to statistics, effective remanufacturing can save energy by $60 \%$, save materials by $70 \%$, and reduce air pollutant emissions by more than $80 \%$. Recycling and remanufacturing can significantly reduce the negative impact of waste products on the environment, which effectively promotes the construction of a resource-saving and environment-friendly society [21]. In addition, some studies have pointed out that recycling, reusing and remanufacturing of waste products can help to reduce the waste of resource and environmental pollution $[17,39]$. Both enterprises and countries can benefit from recycling and remanufacturing. For example, the United States sells about $\$ 100$ billion worth of recycled/remanufactured products every year [31]. Caterpillar, Xerox, and other enterprises have obtained huge economic benefits from the remanufacturing [38]. Therefore, recycling and remanufacturing do not only bring environmental benefits, but also bring economic benefits. Moreover, in recycling and remanufacturing process, the government also plays a crucial role.

According to existing literature, we find that some scholars have considered the retailer's service efforts $[5,19,47,51]$ and government subsidy $[28,44,50]$, respectively. What is different from them is that this paper analyzes the cost-sharing strategies of the manufacturer, the retailer and the third-party in CLSC. Further, in our study, we consider the retailer's service effort and the third-party recycler's recycling subsidy. Specifically, this paper proposes to address the following issues.

(1) What are optimal equilibrium results for four scenarios considering government subsidy and service effort?

(2) What are the impacts of different cost-sharing strategies on decisions of CLSC and social net benefit?

(3) How do crucial parameters (such as government subsidy, service cost coefficient and service sensitivity coefficient) affect the CLSC members and social net benefit?

(4) Which cost-sharing strategy is better for different decision-makers?

To address the above issues, this paper examines a CLSC consisting of a manufacturer, a retailer, and a third-party recycler. Considering the retailer's service effort and the third-party recycler's recycling subsidy, we construct the profit functions under four scenarios (no cost-sharing (N), service investment cost-sharing (I), recycling investment cost-sharing (II), and both service and recycling investment cost-sharing (III)) to discuss the optimal equilibrium results. In addition, we also focus on investigating the impact of crucial parameters on recycling rate, profits and social net benefit.

The rest of the paper is organized as follows. Section 2 provides a literature review related to this research. Model description is showed in Section 3. In Section 4, we analyze the optimal results under four scenarios. We conduct a numerical analysis in Section 5. Finally, we give some management insights, conclude our work and propose future research in Section 6.

\footnotetext{
$1_{\text {http: //www . sohu.com/a/203390864_361701 }}$

$2_{\text {http: //www.gov.cn/zhengce/index.htm }}$
} 


\section{Literature REVIEW}

This paper reviews the literature closely related to our research from three aspects. The first stream discusses the literature on service, including service effort decision and service level decision, as well as the impact of service. The second stream investigates the effects of government interventions, focusing on the influence of a single subsidy strategy and the discussion of multiple subsidy strategies. The last stream describes the literature on the issue of cost-sharing problems in the supply chain.

The first stream focuses on service, the importance of which has been validated in the relevant literature $[2,6,9,13,18,22,34,53]$. Recently, service decisions strategies have received a lot of attentions from scholars. Taylor [41] considered the service effort of the retailer and discussed the manufacturer's channel rebates. The results showed that providing channel rebates is beneficial in promoting service effort. Yao and Liu [55] pointed out that introducing a direct channel generated competitive payoffs and encouraged cost-effective retail service. Dan et al. [4] used a two-stage optimization Stackelberg game model to analyze the effect of retail service, demand growth, and consumer loyalty on the pricing strategies. Xie et al. [51] investigated the forward and reverse channel service and recycling pricing, and used the revenue and cost sharing contract to coordinate the profits. They found that the contract can increase recycling and improve service. Li et al. [20] examined the impact of display effects on manufacturer's pricing and service efforts. Jiang et al. [16] investigated the interaction of a dominant retailer and a manufacturer's strategies on the pricing and service. Their results revealed that the service provided by the retailer has a positive influence on the market demand. Wu et al. [47] indicated that recycling centers still need to improve service to maintain and expand online recycling. Pal et al. [30] considered a retail service-dependent customer demand pattern and discussed the decentralized model involving the vertical Nash game and manufacturer Stackelberg game and centralized model. Further, Sarkar and Pal [34] combined return-refund policy and retail service and analyzed the impact of retail service on profit and pricing decisions under different return strategies. They showed that the retailer makes more profits by adopting a series of effective service improvement measures. In addition, Pal and Sarkar [30] also explored the effect of the promotional effort of the retailer and pointed out that promotional effort can always increase all profits. Mandal and Pal [27] studied the trade credit facilities services of the manufacturer and competing retailers in a carbon emission environment. Schneider and Zielke [36] investigated how offline retailers use service strategies to compensate for the price disadvantages of online channels. They found that mere service usage can partly compensate for price disadvantages. Based on the existing literature, many scholars are devoted to discussing service decision by considering different factors. And they studied the effect of different types of service. Similar to the above literature, this paper also explores the impact of service. But the difference is that this paper discusses the effect of service investment cost-sharing strategy on service decisions.

The second stream is about the government intervention, some literatures have discussed the effect of government intervention $[12,23,24,26,32,52,57]$. Wang and Da [42] facturer to adopt the desired channel structure by setting an appropriate level of subsidy. Moreover, a high subsidy can benefit consumers and the entire supply chain, but not necessarily good for the environment. Wang et al. [44] studied the allocation strategy of government subsidy in the e-waste reverse supply chain. And the results showed that remanufacturing utilization rate has a strong influence on the allocation strategy of government subsidy. Wang et al. [45] analyzed the effect of government subsidy and altruistic preference on recycling decisions and gave the Altruistic Preference Joint Commission' contract to coordinate the system. Zhao et al. [58] constructed a profit distribution model and analyzed the impact of different government subsidy strategies on supply chain competitiveness. Liu et al. [25] explored the production and recycling strategies under different government subsidy schemes. The results showed that subsiding the recycler can stimulate the recycling of end-of-life products and help the recycler increase profit. Zhang et al. [57] analyzed the impact of government funding policies on the choice of remanufacturing models. The results showed that under the government fund policy, the retailer remanufacturing mode is the best choice. But the manufacturer remanufacturing mode is better without government fund policy. The existing literature indicates that the government plays a key role in the process of recycling 
and remanufacturing or other business activities. Compared with the above literature, the government only provides the recycling subsidy for the third-party recycler in this paper. Besides, based on the cost-sharing strategies, this paper focuses on the impact of incentive strategy on decision-making, profits, and social net benefit.

The last stream of literatures related to our paper is about cost-sharing problems [3, 7, 43]. Ghosh and Shah [8] studied the impact of cost-sharing contracts on decisions in a green supply chain. The results showed that the cost-sharing strategy can improve the greening levels and profits. Jiang et al. [15] studied the supply chain performance under decentralized and centralized cost-sharing mechanisms. Yang et al. [54] compared full capacity cost-sharing contracts and partial capacity cost-sharing contracts. Zhou et al. [59] pointed out that under the dual-channel differential and non-differential pricing, the service cost-sharing contract is helpful to stimulate the retailer to improve their service levels. Chakraborty et al. [1] proposed a cost-sharing mechanism between a retailer and a manufacturer. The results showed that both cost-sharing contracts improved the quality and profitability of the supply chain compared to wholesale price contracts. He et al. [11] investigated the impact of three cost-sharing strategies on decision-making. Wu et al. [47] analyzed the different cost-sharing strategies on optimal results. They found that both sales effort cost-sharing and carbon reduction cost-sharing affected the retailer's and manufacturer's decisions. They also found that the fixed government subsidy did not affect the optimal cost-sharing strategies of the retailer and manufacturer. Taleizadeh et al. [40] considered carbon abatement, quality enhancement efforts, and return policies, and proposed the cost-sharing contract in cooperative and non-cooperative forms to find the optimal results. The above literature showed that the cost-sharing strategy can usually achieve coordination effects and improve decisions and profits. However, different from the above literature, this paper proposes three cost-sharing strategies and studies the influence and effectiveness of these strategies. Further, this paper discusses the choice of cost-sharing strategies for managers.

In Table 1, we compare this paper with the above literature. As shown in Table 1, some scholars have conducted in-depth research on service and price decision-making, government intervention, and cost-sharing problems in the supply chain. However, there has been no research on the choice of service and recycling investment cost-sharing strategy and the impact of cost-sharing strategies on decision. In the actual business decision-making, sales service can increase sales, but it will also increase costs. Similarly, to recycle as many used products as possible, the recycler needs to pay more additional costs. Therefore, it is of great significance to coordinate and optimize the profits and decisions. In addition, it is also worthy of attention to consider the effect of government subsidy intervention on recycling and other decisions.

Based on the above literature review, this paper, based on the basic decentralized decision-making model that includes a manufacturer, a retailer, and a third-party recycler, proposes and discusses different cost-sharing strategy models to optimize the profit of each member and provide targeted management decision-making suggestions for enterprises. Therefore, the main contribution of this paper is four-folds. First of all, although there have been studies on service and pricing decisions, those studies mainly focus on the forward supply chain and rarely consider the impact of cost-sharing strategies. But in real life, recycling and remanufacturing have become a trend. Besides, there also exists the problem of cost-sharing. Our research is to solve these problems. Secondly, Combining the relevant literature and the characteristics of the closed-loop supply chain, we construct and solve the Stackelberg game model in four scenarios. Based on the analysis, the influence of different cost-sharing strategies on decision-making is summarized. Thirdly, in previous studies, scholars often overlooked the impact of recycler's recycling costs, recycling subsidy, and consumer service sensitivity coefficients on service decisions and profits, which has also become the main contribution of this paper to the theoretical development of this field. Finally, different cost-sharing strategies will produce different results. Based on these results, we will provide strategy selection and management suggestions for different types of enterprises. 
TABLE 1. Related literature.

\begin{tabular}{|c|c|c|c|c|c|c|c|}
\hline \multirow{2}{*}{ Literature } & \multirow{2}{*}{ Service } & \multicolumn{2}{|c|}{ Pricing } & \multirow{2}{*}{$\begin{array}{l}\text { Cost-sharing } \\
\text { contract }\end{array}$} & \multirow{2}{*}{ Remanufacturing } & \multirow{2}{*}{ Recycling } & \multirow{2}{*}{$\begin{array}{l}\text { Subsidy } \\
\text { target }\end{array}$} \\
\hline & & $\begin{array}{l}\begin{array}{l}\text { Retail } \\
\text { price }\end{array} \\
\end{array}$ & $\begin{array}{l}\text { Recycling } \\
\text { price }\end{array}$ & & & & \\
\hline $\begin{array}{l}\text { Zhou et al. } \\
\text { [59] }\end{array}$ & $\checkmark$ & $\checkmark$ & & $\checkmark$ & & & \\
\hline Xie et al. [51] & $\checkmark$ & & $\checkmark$ & $\checkmark$ & & $\checkmark$ & \\
\hline Wu et al. [47] & $\checkmark$ & & $\checkmark$ & & & $\checkmark$ & \\
\hline He et al. [10] & & $\checkmark$ & & & $\checkmark$ & & $\begin{array}{l}\text { Remanufactured } \\
\text { product }\end{array}$ \\
\hline $\begin{array}{l}\text { Wang et al. } \\
\text { [44] }\end{array}$ & & $\checkmark$ & & & $\checkmark$ & & Remanufacturer \\
\hline $\begin{array}{l}\text { Pal and } \\
\text { Sarkar [30] }\end{array}$ & $\checkmark$ & $\checkmark$ & $\checkmark$ & & & $\checkmark$ & \\
\hline $\begin{array}{l}\text { Wang et al. } \\
\text { [45] }\end{array}$ & $\checkmark$ & & $\checkmark$ & & & $\checkmark$ & $\begin{array}{l}\text { Low-carbon } \\
\text { remanu- } \\
\text { factured } \\
\text { products }\end{array}$ \\
\hline $\begin{array}{l}\text { Ghosh and } \\
\text { Shah [8] }\end{array}$ & & $\checkmark$ & & $\checkmark$ & & $\checkmark$ & \\
\hline Wu et al. [47] & & $\checkmark$ & & $\checkmark$ & & & $\begin{array}{l}\text { Green } \\
\text { product }\end{array}$ \\
\hline $\begin{array}{l}\text { Taleizadeh } \\
\text { et al. }[40]\end{array}$ & & $\checkmark$ & & $\checkmark$ & $\checkmark$ & & \\
\hline $\begin{array}{l}\text { Zhang et al. } \\
\text { [57] }\end{array}$ & $\checkmark$ & $\checkmark$ & & & $\checkmark$ & $\checkmark$ & Remanufacturing \\
\hline This paper & $\checkmark$ & $\checkmark$ & & $\checkmark$ & $\checkmark$ & $\checkmark$ & Recycling \\
\hline
\end{tabular}

\section{MODEL DESCRIPTION}

This paper studies a CLSC composed of a manufacturer, a retailer, and a third-party recycler (the recycler). In the forward channel, the manufacturer is responsible for producing new products and remanufacturing used products, while the retailer is responsible for selling products and providing service for customers. In the reverse channel, the third-party recycler is responsible for recycling the used products and transferring these products to the manufacturer for remanufacturing. This paper introduces the third-party recycler's recycling subsidy and the retailer's service effort. In order to better carry out recycling, the recycler needs to invest some costs in recycling. Similarly, in order to sell more products, the retailer also needs to pay corresponding costs while providing services. Therefore, this paper considers the different cost-sharing strategies, and expects to find the optimal results. The CLSC structure is shown in Figure 1. In order to describe the structure of closed-loop supply chain more accurately, we put forward some assumptions: (1) In four scenarios, each member aims at maximizing its own profits, so there is $p>w>c_{m}$ and $\Delta \geq b \geq A$ for different members, where $\Delta=c_{m}-c_{r}$. (2) Based on Savaskan et al. [35], we assume that there is a non-linear relationship between the recycling investment costs of the recycler and the recycling rate, i.e., $I_{r}=C_{L} \tau^{2}$, with $C_{L}$ sufficiently large. (3) We assume that the demand is $D=\phi-\beta p+\gamma s$ [20]. Also, based on Wu et al. [47], we assume that the service investment costs are $I_{s}=\frac{k s^{2}}{2}$.

In this paper, the notations are shown in Table 2. Note. The superscript $\mathrm{N}^{*}$ represents the optimal decisions under no cost-sharing $(\mathrm{N})$. The superscript $\mathrm{I}^{*}$ represents the optimal decisions under service investment costsharing (I). The superscript II* represents the optimal decisions under recycling investment cost-sharing (II). The superscript III* represents the optimal decisions under both service and recycling investment cost-sharing 


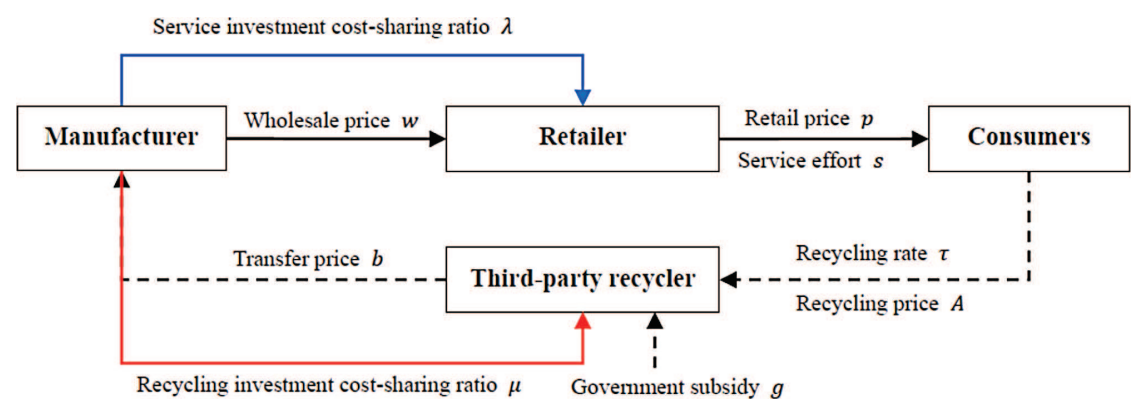

FiguRE 1. The structure of CLSC.

TABle 2. Notations.

\begin{tabular}{ll}
\hline \hline Parameters & Explanations \\
\hline$\phi$ & The market size \\
$\beta$ & The sensitivity coefficient of the retail price \\
$\gamma$ & The sensitivity coefficient of service effort \\
$c_{m}$ & The unit cost of manufacturing new products \\
$c_{r}$ & The unit cost of remanufacturing recycled products \\
$A$ & The unit recycling price of the products given by the third-party \\
$k$ & The exchanging coefficient between the service effort and the investment \\
$\Delta$ & The unit cost saving from remanufacturing, $\Delta=c_{m}-c_{r}$ \\
$g$ & The unit recycling subsidy given by the government \\
$\lambda$ & The service investment cost-sharing ratio of the manufacturer, $0<\lambda<1$ \\
$\mu$ & The recycling investment cost-sharing ratio of the manufacturer, $0<\mu<1$ \\
$C_{L}$ & The exchanging coefficient between the recycling rate and the investment \\
\hline Decision variables & \\
\hline$p$ & The unit retail price \\
$s$ & The service effort \\
$w$ & The unit wholesale price \\
$b$ & The unit transfer price \\
$\tau$ & The recycling rate \\
\hline Functions & \\
\hline$\pi_{i}^{j}$ & The profit of $i$ under $j$ scenario, $i=c, m, r, t, j=\mathrm{N}$, I, II, III \\
$G^{j}$ & The total government subsidy under $j$ scenario, $j=\mathrm{N}, \mathrm{I}, \mathrm{II}, \mathrm{III}$ \\
$S^{j}$ & The social net benefit under $j$ scenario, $j=\mathrm{N}, \mathrm{I}, \mathrm{II}$, III \\
\hline
\end{tabular}

(III). And the subscripts $c, m, r$ and $t$ represent the CLSC, manufacturer, retailer and third-party recycler, respectively.

\section{Model SOlution}

Based on the above analysis, the profit functions of the retailer, the manufacturer and the third-party recycler can be constructed for the four scenarios: (1) No cost-sharing; (2) Service investment cost-sharing; (3) Recycling investment cost-sharing; (4) Both service and recycling investment cost-sharing. The four scenarios are all discussed based on decentralized decision-making, and this paper considers that the manufacturer is the leader of Stackelberg game, the retailer and the third-party recycler are the followers, so that each member makes independent decisions with the goal of maximizing their own profits. Then, the game theory is used as the 
applied optimization tool, and the optimal results can be obtained. In the following, the specific analysis is provided.

\subsection{Scenario 1: No cost-sharing (N)}

In this scenario, the manufacturer neither shares the retailer's service investment nor the third-party's recycling investment. According to the above description, the manufacturer first decides the wholesale price and the transfer price, and secondly, the retailer decides the retail price and service effort, and the third party decides the recycling rate. From this, we can obtain response function as follows:

$$
\begin{aligned}
& \max _{w, b} \pi_{m}^{N}=\left(w-c_{m}\right)(\phi-\beta p+\gamma s)+\tau(\Delta-b)(\phi-\beta p+\gamma s) \\
& \text { s.t. } \\
& \max _{p, s} \pi_{r}^{N}=(p-w)(\phi-\beta p+\gamma s)-\frac{k s^{2}}{2} \\
& \max _{\tau} \pi_{t}^{N}=\tau(\phi-\beta p+\gamma s)(\Delta-b+g)-C_{L} \tau^{2} .
\end{aligned}
$$

Using backward induction, we can obtain the Proposition 4.1.

Proposition 4.1. The third-party's profit is a strictly concave function of recycling rate. The retailer's profit is a concave function of retail price and service effort if and only if $2 \beta k-\gamma^{2}>0$. The manufacturer's profit is a concave function of wholesale price and transfer price if and only if $8\left(2 k \beta-\gamma^{2}\right) C_{L}-k \beta^{2}(\Delta-A+g)^{2}>0$.

According to Proposition 4.1, the optimal decisions of the retailer, the third-party, and the manufacturer are

$$
\begin{aligned}
p^{N^{*}} & =\frac{4\left[\left(3 k \beta-\gamma^{2}\right) \phi+\beta\left(k \beta-\gamma^{2}\right) c_{m}\right] C_{L}-k \beta^{2}(\Delta-A+g)^{2} \phi}{\beta\left[8\left(2 k \beta-\gamma^{2}\right) C_{L}-k \beta^{2}(\Delta-A+g)^{2}\right]} \\
w^{N^{*}} & =\frac{4\left(2 k \beta-\gamma^{2}\right)\left(\phi+\beta c_{m}\right) C_{L}-k \beta^{2}(\Delta-A+g)^{2} \phi}{\beta\left[8\left(2 k \beta-\gamma^{2}\right) C_{L}-k \beta^{2}(\Delta-A+g)^{2}\right]} \\
s^{N^{*}} & =\frac{4 \gamma\left(\phi-\beta c_{m}\right) C_{L}}{8\left(2 k \beta-\gamma^{2}\right) C_{L}-k \beta^{2}(\Delta-A+g)^{2}} \\
\tau^{\mathrm{N}^{*}} & =\frac{k \beta\left(\phi-\beta c_{m}\right)(\Delta-A+g)}{8\left(2 k \beta-\gamma^{2}\right) C_{L}-k \beta^{2}(\Delta-A+g)^{2}} \\
b^{\mathrm{N}^{*}} & =\frac{1}{2}(\Delta+A-g) .
\end{aligned}
$$

Furthermore, the optimal profits of the retailer, third-party, and manufacturer, can be obtained, respectively, i.e.,

$$
\begin{aligned}
\pi_{t}^{\mathrm{N}^{*}} & =\frac{k^{2} \beta^{2}\left(\phi-\beta c_{m}\right)^{2}(\Delta-A+g)^{2} C_{L}}{\left[8\left(2 k \beta-\gamma^{2}\right) C_{L}-k \beta^{2}(\Delta-A+g)^{2}\right]^{2}} \\
\pi_{r}^{\mathrm{N}^{*}} & =\frac{8 k\left(2 k \beta-\gamma^{2}\right)\left(\phi-\beta c_{m}\right)^{2} C_{L}^{2}}{\left[8\left(2 k \beta-\gamma^{2}\right) C_{L}-k \beta^{2}(\Delta-A+g)^{2}\right]^{2}} \\
\pi_{m}^{\mathrm{N}^{*}} & =\frac{2 k\left(\phi-\beta c_{m}\right)^{2} C_{L}}{8\left(2 k \beta-\gamma^{2}\right) C_{L}-k \beta^{2}(\Delta-A+g)^{2}} .
\end{aligned}
$$


Based on the above optimal decisions and profits, we can also obtain the profit of CLSC, subsidy cost, and the social net benefit,

$$
\begin{aligned}
\pi_{c}^{\mathrm{N}^{*}} & =\frac{k\left(\phi-\beta c_{m}\right)^{2} C_{L}\left[24\left(2 k \beta-\gamma^{2}\right) C_{L}-k \beta^{2}(\Delta-A+g)^{2}\right]}{\left[8\left(2 k \beta-\gamma^{2}\right) C_{L}-k \beta^{2}(\Delta-A+g)^{2}\right]^{2}} \\
G^{\mathrm{N}^{*}} & =\frac{4 g k^{2} \beta^{2}(\Delta-A+g)\left(\phi-\beta c_{m}\right)^{2} C_{L}}{\left[8\left(2 k \beta-\gamma^{2}\right) C_{L}-k \beta^{2}(\Delta-A+g)^{2}\right]^{2}} \\
S^{\mathrm{N}^{*}} & =\frac{k\left(\phi-\beta c_{m}\right)^{2} C_{L}\left(24\left(2 k \beta-\gamma^{2}\right) C_{L}-k \beta^{2}(\Delta-A+g)(\Delta-A+5 g)\right)}{\left[8\left(2 k \beta-\gamma^{2}\right) C_{L}-k \beta^{2}(\Delta-A+g)^{2}\right]^{2}} .
\end{aligned}
$$

Proof. The proof can be seen in the Appendix A.1.

\subsection{Scenario 2: Service investment cost-sharing (I)}

In this scenario, this paper examines the improvement effect of the manufacturer sharing the retailer's service investment costs. The purpose is to discuss whether each member's profit and recycling rate will be improved when the manufacturer agrees to share the retailer's service investment costs. According to the same idea as in Scenario 1, each member makes independent decisions. Therefore, the objective profit of manufacturer can be expressed as:

$$
\begin{aligned}
& \max _{w, b} \pi_{m}^{I}=\left(w-c_{m}\right)(\phi-\beta p+\gamma s)+\tau(\Delta-b)(\phi-\beta p+\gamma s)-\lambda \frac{k s^{2}}{2} \\
& \text { s.t. } \\
& \max _{p, s} \pi_{r}^{I}=(p-w)(\phi-\beta p+\gamma s)-(1-\lambda) \frac{k s^{2}}{2} \\
& \max _{\tau} \pi_{t}^{I}=\tau(\phi-\beta p+\gamma s)(\Delta-b+g)-C_{L} \tau^{2} .
\end{aligned}
$$

According to backward induction, we first solve the retailer's problem and the third-party's problem, then we solve the manufacturer's problem. Finally, we can obtain the following Proposition 4.2.

Proposition 4.2. The third-party's profit is a strictly concave function of recycling rate. The retailer's profit is a concave function of retail price and service effort if and only if $2 \beta k(1-\lambda)-\gamma^{2}>0$. The manufacturer's profit is a concave function of wholesale price and transfer price if and only if $k \beta^{2}(\Delta-A+g)^{2}(1-\lambda)^{2}-$ $8\left(2 k \beta(1-\lambda)^{2}-\gamma^{2}(1-2 \lambda)\right) C_{L}<0$.

Based on the above proposition, the optimal decisions in this scenario are:

$$
\begin{aligned}
p^{I^{*}} & =\frac{4\left[\left(3 k \beta(1-\lambda)^{2}-\gamma^{2}(1-3 \lambda)\right) \phi+\beta\left(k \beta(1-\lambda)-\gamma^{2}\right)(1-\lambda) c_{m}\right] C_{L}-k \beta^{2}(\Delta-A+g)^{2} \phi(1-\lambda)^{2}}{\beta\left[8\left(2 k \beta(1-\lambda)^{2}-\gamma^{2}(1-2 \lambda)\right) C_{L}-k \beta^{2}(\Delta-A+g)^{2}(1-\lambda)^{2}\right]} \\
w^{\mathrm{I}^{*}} & =\frac{4\left[\left(2 k \beta(1-\lambda)^{2}-\gamma^{2}(1-3 \lambda)\right) \phi+\beta\left(2 k \beta(1-\lambda)-\gamma^{2}\right)(1-\lambda) c_{m}\right] C_{L}-k \beta^{2}(\Delta-A+g)^{2} \phi(1-\lambda)^{2}}{\beta\left[8\left(2 k \beta(1-\lambda)^{2}-\gamma^{2}(1-2 \lambda)\right) C_{L}-k \beta^{2}(\Delta-A+g)^{2}(1-\lambda)^{2}\right]} \\
s^{\mathrm{I}^{*}} & =\frac{4 \gamma\left(\phi-\beta c_{m}\right) C_{L}(1-\lambda)}{8\left(2 k \beta(1-\lambda)^{2}-\gamma^{2}(1-2 \lambda)\right) C_{L}-k \beta^{2}(\Delta-A+g)^{2}(1-\lambda)^{2}}
\end{aligned}
$$




$$
\begin{aligned}
\tau^{\mathrm{I}^{*}} & =\frac{k \beta\left(\phi-\beta c_{m}\right)(\Delta-A+g)(1-\lambda)^{2}}{8\left(2 k \beta(1-\lambda)^{2}-\gamma^{2}(1-2 \lambda)\right) C_{L}-k \beta^{2}(\Delta-A+g)^{2}(1-\lambda)^{2}} \\
b^{I^{*}} & =\frac{1}{2}(\Delta+A-g) .
\end{aligned}
$$

Furthermore, the optimal profits of the retailer, third-party, and manufacturer can be determined, respectively, i.e.,

$$
\begin{aligned}
\pi_{t}^{\mathrm{I}^{*}} & =\frac{k^{2} \beta^{2}\left(\phi-\beta c_{m}\right)^{2}(\Delta-A+g)^{2} C_{L}(1-\lambda)^{4}}{\left[8\left(2 k \beta(1-\lambda)^{2}-\gamma^{2}(1-2 \lambda)\right) C_{L}-k \beta^{2}(\Delta-A+g)^{2}(1-\lambda)^{2}\right]^{2}} \\
\pi_{r}^{\mathrm{I}^{*}} & =\frac{8 k\left(2 k \beta(1-\lambda)-\gamma^{2}\right)(1-\lambda)^{3}\left(\phi-\beta c_{m}\right)^{2} C_{L}^{2}}{\left[8\left(2 k \beta(1-\lambda)^{2}-\gamma^{2}(1-2 \lambda)\right) C_{L}-k \beta^{2}(\Delta-A+g)^{2}(1-\lambda)^{2}\right]^{2}} \\
\pi_{m}^{\mathrm{I}^{*}} & =\frac{2 k\left(\phi-\beta c_{m}\right)^{2} C_{L}(1-\lambda)^{2}}{8\left(2 k \beta(1-\lambda)^{2}-\gamma^{2}(1-2 \lambda)\right) C_{L}-k \beta^{2}(\Delta-A+g)^{2}(1-\lambda)^{2}} .
\end{aligned}
$$

Based on above optimal results, we can also determine the profit of CLSC, subsidy cost and social net benefit,

$$
\begin{aligned}
\pi_{c}^{\mathrm{I}^{*}}= & \frac{k(1-\lambda)^{2}\left(\phi-\beta c_{m}\right)^{2} C_{L}\left[8\left(6 k \beta(1-\lambda)^{2}-\gamma^{2}(3-5 \lambda)\right) C_{L}-k \beta^{2}(\Delta-A+g)^{2}(1-\lambda)^{2}\right]}{\left[8\left(2 k \beta(1-\lambda)^{2}-\gamma^{2}(1-2 \lambda)\right) C_{L}-k \beta^{2}(\Delta-A+g)^{2}(1-\lambda)^{2}\right]^{2}} \\
G^{\mathrm{I}^{*}} & =\frac{4 g k^{2} \beta^{2}(\Delta-A+g)\left(\phi-\beta c_{m}\right)^{2} C_{L}(1-\lambda)^{4}}{\left[8\left(2 k \beta(1-\lambda)^{2}-\gamma^{2}(1-2 \lambda)\right) C_{L}-k \beta^{2}(\Delta-A+g)^{2}(1-\lambda)^{2}\right]^{2}} \\
S^{\mathrm{I}^{*}} & =\frac{k(1-\lambda)^{2}\left(\phi-\beta c_{m}\right)^{2} C_{L}\left[8\left(6 k \beta(1-\lambda)^{2}-\gamma^{2}(3-5 \lambda)\right) C_{L}-k \beta^{2}(\Delta-A+g)(\Delta-A+5 g)(1-\lambda)^{2}\right]}{\left[8\left(2 k \beta(1-\lambda)^{2}-\gamma^{2}(1-2 \lambda)\right) C_{L}-k \beta^{2}(\Delta-A+g)^{2}(1-\lambda)^{2}\right]^{2}} .
\end{aligned}
$$

Proof. The proof can be seen in the Appendix A.2.

\subsection{Scenario 3: Recycling investment cost-sharing (II)}

In this scenario, the manufacturer only shares the recycling investment cost of the third-party, but the manufacturer does not share the service investment cost of the retailer. The purpose is to discuss whether it is a good coordination strategy for the manufacturer to share the recycling investment costs of the third-party recycler compared to sharing the service investment costs. The modeling and analysis ideas are similar to the above scenarios. Therefore, the objective profit of manufacturer can be expressed as:

$$
\begin{aligned}
& \max _{w, b} \pi_{m}^{\mathrm{II}}=\left(w-c_{m}\right)(\phi-\beta p+\gamma s)+\tau(\Delta-b)(\phi-\beta p+\gamma s)-\mu C_{L} \tau^{2} \\
& \text { s.t. } \\
& \max _{p, s} \pi_{r}^{\mathrm{II}}=(p-w)(\phi-\beta p+\gamma s)-\frac{k s^{2}}{2} \\
& \max _{\tau} \pi_{t}^{\mathrm{II}}=\tau(\phi-\beta p+\gamma s)(\Delta-b+g)-(1-\mu) C_{L} \tau^{2} .
\end{aligned}
$$

According to above objective functions, we can obtain the Proposition 4.3. 
Proposition 4.3. The third-party's profit is a strictly concave function of recycling rate. The retailer's profit is a concave function of retail price and service effort if and only if $2 \beta k-\gamma^{2}>0$. The manufacturer's profit is a concave function of wholesale price and transfer price if and only if $k \beta^{2}(\Delta-A+g)^{2}-4\left(2 k \beta-\gamma^{2}\right)(2-\mu) C_{L}<$ 0 .

According to this proposition, the optimal decisions in this scenario are

$$
\begin{aligned}
p^{\mathrm{I}{ }^{*}} & =\frac{2(2-\mu)\left[\left(3 k \beta-\gamma^{2}\right) \phi+\beta\left(k \beta-\gamma^{2}\right) c_{m}\right] C_{L}-k \beta^{2}(\Delta-A+g)^{2} \phi}{\beta\left[4\left(2 k \beta-\gamma^{2}\right)(2-\mu) C_{L}-k \beta^{2}(\Delta-A+g)^{2}\right]} \\
w^{\mathrm{II}} & =\frac{2(2-\mu)\left(2 k \beta-\gamma^{2}\right)\left(\phi+\beta c_{m}\right) C_{L}-k \beta^{2}(\Delta-A+g)^{2} \phi}{\beta\left[4\left(2 k \beta-\gamma^{2}\right)(2-\mu) C_{L}-k \beta^{2}(\Delta-A+g)^{2}\right]} \\
s^{\mathrm{I}} & =\frac{2(2-\mu) \gamma\left(\phi-\beta c_{m}\right) C_{L}}{4\left(2 k \beta-\gamma^{2}\right)(2-\mu) C_{L}-k \beta^{2}(\Delta-A+g)^{2}} \\
\tau^{\mathrm{II}^{*}} & =\frac{k \beta\left(\phi-\beta c_{m}\right)(\Delta-A+g)}{4\left(2 k \beta-\gamma^{2}\right)(2-\mu) C_{L}-k \beta^{2}(\Delta-A+g)^{2}} \\
b^{\mathrm{I}} & =\Delta-\frac{\Delta-A+g}{2-\mu} .
\end{aligned}
$$

According to above optimal decisions, we can obtain the optimal profits,

$$
\begin{aligned}
\pi_{t}^{\mathrm{II}} & =\frac{k^{2} \beta^{2}\left(\phi-\beta c_{m}\right)^{2}(\Delta-A+g)^{2} C_{L}(1-\mu)}{\left[4\left(2 k \beta-\gamma^{2}\right)(2-\mu) C_{L}-k \beta^{2}(\Delta-A+g)^{2}\right]^{2}} \\
\pi_{r}^{\mathrm{II}} & =\frac{2 k(2-\mu)^{2}\left(2 k \beta-\gamma^{2}\right)\left(\phi-\beta c_{m}\right)^{2} C_{L}^{2}}{\left[4\left(2 k \beta-\gamma^{2}\right)(2-\mu) C_{L}-k \beta^{2}(\Delta-A+g)^{2}\right]^{2}} \\
\pi_{m}^{\mathrm{II}} & =\frac{(2-\mu) k\left(\phi-\beta c_{m}\right)^{2} C_{L}}{4\left(2 k \beta-\gamma^{2}\right)(2-\mu) C_{L}-k \beta^{2}(\Delta-A+g)^{2}} .
\end{aligned}
$$

In addition, we can obtain the profit of CLSC, subsidy cost and the social net benefit.

$$
\begin{aligned}
\pi_{c}^{\mathrm{II}} & =\frac{k\left(\phi-\beta c_{m}\right)^{2} C_{L}\left[6(2-\mu)^{2}\left(2 k \beta-\gamma^{2}\right) C_{L}-k \beta^{2}(\Delta-A+g)^{2}\right]}{\left[4\left(2 k \beta-\gamma^{2}\right)(2-\mu) C_{L}-k \beta^{2}(\Delta-A+g)^{2}\right]^{2}} \\
G^{\mathrm{II}^{*}} & =\frac{4 g k^{2} \beta^{2}(\Delta-A+g)\left(\phi-\beta c_{m}\right)^{2} C_{L}(2-\mu)}{\left[4\left(2 k \beta-\gamma^{2}\right)(2-\mu) C_{L}-k \beta^{2}(\Delta-A+g)^{2}\right]^{2}} \\
S^{\mathrm{II}} & =\frac{k\left(\phi-\beta c_{m}\right)^{2} C_{L}\left(6(2-\mu)^{2}\left(2 k \beta-\gamma^{2}\right) C_{L}-k \beta^{2}(\Delta-A+g)(\Delta-A+5 g-2 g \mu)\right)}{\left[4\left(2 k \beta-\gamma^{2}\right)(2-\mu) C_{L}-k \beta^{2}(\Delta-A+g)^{2}\right]^{2}} .
\end{aligned}
$$

Proof. The proof can be seen in the Appendix A.3.

\subsection{Scenario 4: Both service and recycling investment cost-sharing (III)}

In this scenario, the manufacturer not only shares the service investment cost of the retailer, but also shares the recycling investment cost of the third-party. The purpose is to discuss whether the manufacturer sharing 
both service investment and recycling investment costs can enable members to obtain more profits and better social net benefits. The analysis process is similar to the above scenarios. Therefore, the objective profit of manufacturer can be expressed as:

$$
\begin{aligned}
& \max _{w, b} \pi_{m}^{\mathrm{III}}=\left(w-c_{m}\right)(\phi-\beta p+\gamma s)+\tau(\Delta-b)(\phi-\beta p+\gamma s)-\lambda \frac{k s^{2}}{2}-\mu C_{L} \tau^{2} \\
& \text { s.t. } \\
& \max _{p, s} \pi_{r}^{\mathrm{III}}=(p-w)(\phi-\beta p+\gamma s)-(1-\lambda) \frac{k s^{2}}{2} \\
& \max _{\tau} \pi_{t}^{\mathrm{III}}=\tau(\phi-\beta p+\gamma s)(\Delta-b+g)-(1-\mu) C_{L} \tau^{2} .
\end{aligned}
$$

According to the above objective function, we can obtain the following Proposition 4.4.

Proposition 4.4. The third-party's profit is a strictly concave function of recycling rate. The retailer's profit is a concave function of retail price and service effort if and only if $2 \beta k(1-\lambda)-\gamma^{2}>0$. The manufacturer's profit is a concave function of wholesale price and transfer price if and only if $k \beta^{2}(\Delta-A+g)^{2}(1-\lambda)^{2}-$ $4\left(2 k \beta(1-\lambda)^{2}-\gamma^{2}(1-2 \lambda)\right)(2-\mu) C_{L}<0$.

It can be seen from Proposition 4.4, the optimal decisions in this scenario are

$$
\begin{aligned}
p^{\mathrm{II} \mathrm{I}^{*}} & =\frac{2(2-\mu)\left[\left(3 k \beta(1-\lambda)^{2}-(1-3 \lambda) \gamma^{2}\right) \phi+\beta\left(k \beta(1-\lambda)-\gamma^{2}\right)(1-\lambda) c_{m}\right] C_{L}-(1-\lambda)^{2} k \beta^{2}(\Delta-A+g)^{2} \phi}{\beta\left[4\left(2 k \beta(1-\lambda)^{2}-\gamma^{2}(1-2 \lambda)\right)(2-\mu) C_{L}-k \beta^{2}(\Delta-A+g)^{2}(1-\lambda)^{2}\right]} \\
w^{\mathrm{III}} & =\frac{2(2-\mu)\left[\left(2 k \beta(1-\lambda)^{2}-\gamma^{2}(1-3 \lambda)\right) \phi+\beta\left(2 k \beta(1-\lambda)-\gamma^{2}\right)(1-\lambda) c_{m}\right] C_{L}-k \beta^{2}(\Delta-A+g)^{2} \phi(1-\lambda)^{2}}{\beta\left[4\left(2 k \beta(1-\lambda)^{2}-\gamma^{2}(1-2 \lambda)\right)(2-\mu) C_{L}-k \beta^{2}(\Delta-A+g)^{2}(1-\lambda)^{2}\right]} \\
s^{\mathrm{III}} & =\frac{2 \gamma(1-\lambda)(2-\mu)\left(\phi-\beta c_{m}\right) C_{L}}{4\left(2 k \beta(1-\lambda)^{2}-\gamma^{2}(1-2 \lambda)\right)(2-\mu) C_{L}-k \beta^{2}(\Delta-A+g)^{2}(1-\lambda)^{2}} \\
\tau^{\mathrm{III}} & =\frac{k \beta\left(\phi-\beta c_{m}\right)(\Delta-A+g)(1-\lambda)^{2}}{4\left(2 k \beta(1-\lambda)^{2}-\gamma^{2}(1-2 \lambda)\right)(2-\mu) C_{L}-k \beta^{2}(\Delta-A+g)^{2}(1-\lambda)^{2}} \\
b^{\mathrm{II} I^{*}} & =\Delta-\frac{\Delta-A+g}{2-\mu} .
\end{aligned}
$$

Based on above optimal decisions, we can obtain the profits of the retailer, third-party and manufacturer.

$$
\begin{aligned}
\pi_{t}^{\mathrm{III}} & =\frac{k^{2} \beta^{2}\left(\phi-\beta c_{m}\right)^{2}(\Delta-A+g)^{2} C_{L}(1-\lambda)^{4}(1-\mu)}{\left[4\left(2 k \beta(1-\lambda)^{2}-\gamma^{2}(1-2 \lambda)\right)(2-\mu) C_{L}-k \beta^{2}(\Delta-A+g)^{2}(1-\lambda)^{2}\right]^{2}} \\
\pi_{r}^{\mathrm{III}} & =\frac{2(2-\mu)^{2} k\left(2 k \beta(1-\lambda)-\gamma^{2}\right)(1-\lambda)^{3}\left(\phi-\beta c_{m}\right)^{2} C_{L}^{2}}{\left[4\left(2 k \beta(1-\lambda)^{2}-\gamma^{2}(1-2 \lambda)\right)(2-\mu) C_{L}-k \beta^{2}(\Delta-A+g)^{2}(1-\lambda)^{2}\right]^{2}} \\
\pi_{m}^{\mathrm{III}} & =\frac{(2-\mu) k\left(\phi-\beta c_{m}\right)^{2} C_{L}(1-\lambda)^{2}}{4\left(2 k \beta(1-\lambda)^{2}-\gamma^{2}(1-2 \lambda)\right)(2-\mu) C_{L}-k \beta^{2}(\Delta-A+g)^{2}(1-\lambda)^{2}} .
\end{aligned}
$$

In addition, we can also obtain the profit of CLSC, subsidy cost and social net benefit.

$$
\begin{aligned}
\pi_{c}^{\mathrm{III}} & =\frac{k(1-\lambda)^{2}\left(\phi-\beta c_{m}\right)^{2} C_{L}\left[2(2-\mu)^{2}\left(6 k \beta(1-\lambda)^{2}-\gamma^{2}(3-5 \lambda)\right) C_{L}-k \beta^{2}(\Delta-A+g)^{2}(1-\lambda)^{2}\right]}{\left[4\left(2 k \beta(1-\lambda)^{2}-\gamma^{2}(1-2 \lambda)\right)(2-\mu) C_{L}-k \beta^{2}(\Delta-A+g)^{2}(1-\lambda)^{2}\right]^{2}} \\
G^{\mathrm{III}} & =\frac{2(2-\mu) g k^{2} \beta^{2}(\Delta-A+g)\left(\phi-\beta c_{m}\right)^{2} C_{L}(1-\lambda)^{4}}{\left[4\left(2 k \beta(1-\lambda)^{2}-\gamma^{2}(1-2 \lambda)\right)(2-\mu) C_{L}-k \beta^{2}(\Delta-A+g)^{2}(1-\lambda)^{2}\right]^{2}}
\end{aligned}
$$


$S^{\mathrm{II} \mathrm{I}^{*}}=\frac{k(1-\lambda)^{2}\left(\phi-\beta c_{m}\right)^{2} C_{L}\left[2(2-\mu)^{2}\left(6 k \beta(1-\lambda)^{2}-\gamma^{2}(3-5 \lambda)\right) C_{L}-k \beta^{2}(\Delta-A+g)(\Delta-A+5 g-2 g \mu)(1-\lambda)^{2}\right]}{\left[4\left(2 k \beta(1-\lambda)^{2}-\gamma^{2}(1-2 \lambda)\right)(2-\mu) C_{L}-k \beta^{2}(\Delta-A+g)^{2}(1-\lambda)^{2}\right]^{2}}$.

Proof. The proof can be seen in the Appendix A.4.

\section{NUMERICAL ANALYSIS}

Due to the complexity of the comparative results, it is difficult to directly determine which strategy is better. Therefore, we use numerical analysis to discuss the selection of strategies and the comparison of results in different scenarios. In order to more clearly show the impact of changes in key parameters on the equilibrium results, this section first discusses the impact of changes in the cost-sharing ratios on the equilibrium results, profits and social net benefit. Secondly, given the cost-sharing ratios, the impact of changes in the service investment cost coefficient, government recycling subsidy and consumer service sensitivity coefficient on the recycling rate, profits and social net benefit are discussed separately.

\subsection{The effect of $\lambda$ and $\mu$ on optimal results}

We assume $\phi=100, c_{m}=60, c_{r}=30, A=10, k=5, \beta=1, C_{L}=1500, \gamma=2, \Delta=30, g=20$. In order to better visualize the changes in retail price, service effort, recycling rate, system profit and social net benefit, this paper analyzes the results under four scenarios through the changes in $\lambda$ and $\mu$. Given $\lambda \in[0,1]$ and $\mu \in[0,1]$, the impacts can be analyzed as shown in Figures 2-9. It can be seen more intuitively from Figure 2 that the trend of retail price in Scenario 3 (II) in is not obvious and the retail price in this scenario is the smallest. Under the joint effect of $\lambda$ and $\mu$, the retail price in Scenario 4 (III) first increases and then decreases with the increase of $\lambda$ and $\mu$. This indicates that the change in the outcome brought by $\lambda$ is greater than that brought by $\mu$. For example, the retail price in Scenario 4 (III) is not always smaller than the retail price in Scenario 2 (I). when $\lambda$ is less than about 0.25 , the retail price in Scenario 2 (I) is larger than the retail price in Scenario 4 (III). In addition, with $\lambda$ increasing, the retail price in Scenario 2 (I) and Scenario 4 (III) will decrease. When $\lambda=1$, that is, the manufacturer fully shares the retailer's service investment, the retail price at this time is greater than the retail price when the manufacturer does not share the retailer's service investment at all. This means that service investment cost-sharing is effective for the retailer to improve the retail price.

As can be seen in Figure 3, it is easy to know that the service effort in Scenario 2 (I) first increases and then decreases with the increase of $\lambda$. Similarly, the service effort in Scenario 3 (II) increases with the increase of $\mu$. Under the joint effect of $\lambda$ and $\mu$, the service effort in Scenario 4 (III) first increases and then decreases with the increase of $\lambda$ and $\mu$. Within a certain range, the service effort in Scenario 3 (II) is superior to that in Scenario 2 (I) and Scenario 4 (III). We can also see from the figure that appropriate cost-sharing ratio can optimize the retailer's service effort decision-making.

In Figure 4, the recycling rate in Scenario 2 (I) decreases in $\lambda$ and the recycling rate in Scenario 3 (II) increases in $\mu$. Under the joint effect of $\lambda$ and $\mu$, the recycling rate in Scenario 4 (III) decreases with the increase of $\lambda$ and $\mu$. This indicates that the positive effect of $\mu$ on the recycling rate is less than the negative effect of $\lambda$ on the recycling rate. From the figure, it is found that the recycling rate in Scenario 3 (II) is strongly dominant. When the service investment cost-sharing ratio is enough low and the recycling investment cost-sharing ratio is enough large, the recycling rate in Scenario 4 (III) is higher than the recycling rate in Scenario 1 (N). In short, sharing the recycling investment is an effective strategy to improve the recycling rate. However, sharing the service investment is not conducive to promoting recycling.

As shown in Figure 5, the profit of retailer in Scenario 3 (II) is the highest, while the profit of retailer in Scenario 2 (I) is the lowest. This means that sharing the service investment is not beneficial to the retailer. However, sharing the recycling investment is more beneficial to the retailer. It is not difficult to explain this phenomenon. When existing the service investment cost-sharing, the retail price and service effort will increase to varying degrees, but the impact of retail price is greater than the impact of service effort, which leads to a 


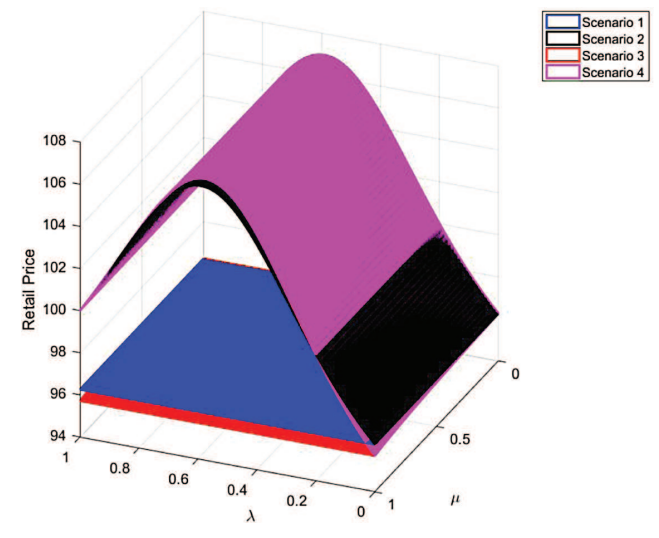

Figure 2. The impact of $\lambda$ and $\mu$ on $p$.

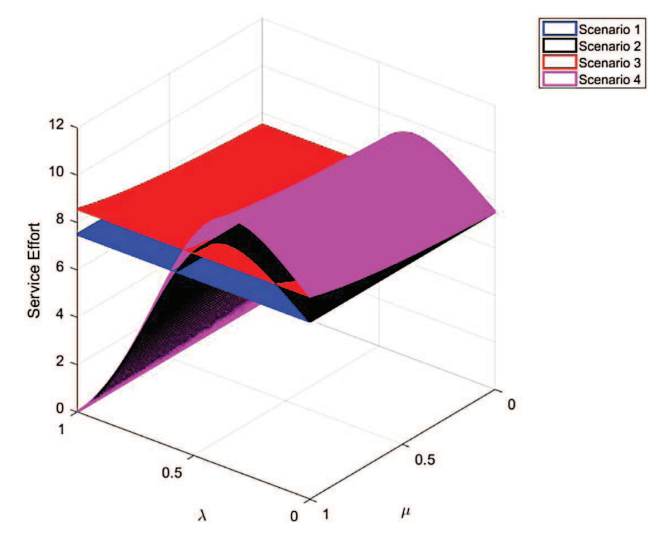

Figure 3. The impact of $\lambda$ and $\mu$ on $s$.

decline in demand, which in turn leads to lower for the retailer. In addition, even if the negative effect caused by $\lambda$ is greater than the positive effect brought by $\mu$, when the cost-sharing ratio is within a certain range, the profit of the retailer in Scenario 4 (III) is better than that in Scenario 1 (N). This reveals that sharing service investment and recycling investment can also bring benefits to the retailer.

As for the third-party's profit (see Fig. 6), the profit in Scenario 3 (II) is optimal among four scenarios when $\mu$ is less than about 0.5. Whereas under the joint effect of $\mu$ and $\lambda$, the profit in Scenario 4 (III) can be better than that in Scenario $1(\mathrm{~N})$. This shows that when the service investment cost-sharing ratio and recycling investment cost-sharing ratio are both low, the third-party can get more profits from it. Moreover, we can also notice that sharing the service investment is not beneficial to the third-party.

As $\mu$ and $\lambda$ increase, the profit of manufacturer in Scenario 4 (III) increases, but it is still less than the manufacturer's profit in other scenarios (see Fig. 7). For the manufacturer, all cost-sharing strategies have negative impacts on its profit. Among the three cost-sharing strategies, sharing as little service investment as possible is able to minimize the loss of manufacturer's profit. In other cost-sharing strategies, sharing investment costs is harmful to the manufacturer.

As shown in Figure 8, it is easy to know that the profit of CLSC in Scenario 2 (I) decreases with $\lambda$ increasing. Similarly, the profit of CLSC in Scenario 3 (II) increases with $\mu$ increasing. Under the combined effect of $\lambda$ and $\mu$, the profit of CLSC in Scenario 4 (III) decreases with $\lambda$ and $\mu$ increasing. It can be found that the profit 

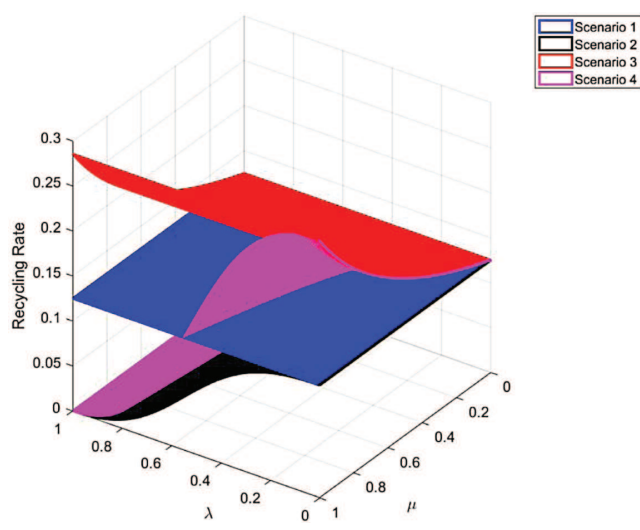

Figure 4. The impact of $\lambda$ and $\mu$ on $\tau$.
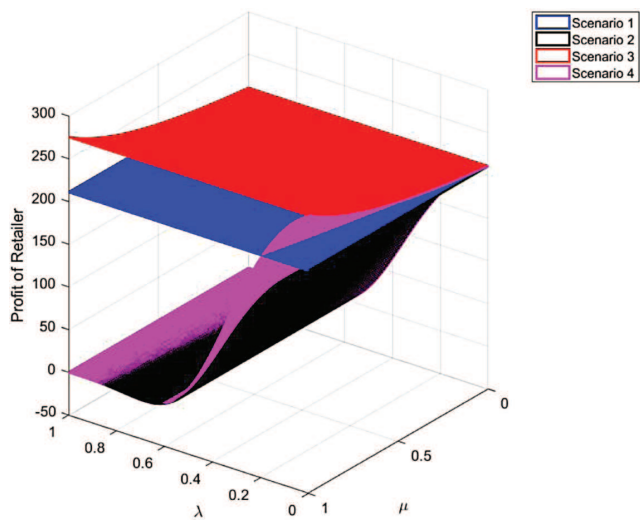

Figure 5. The impact of $\lambda$ and $\mu$ on $\pi_{r}$.

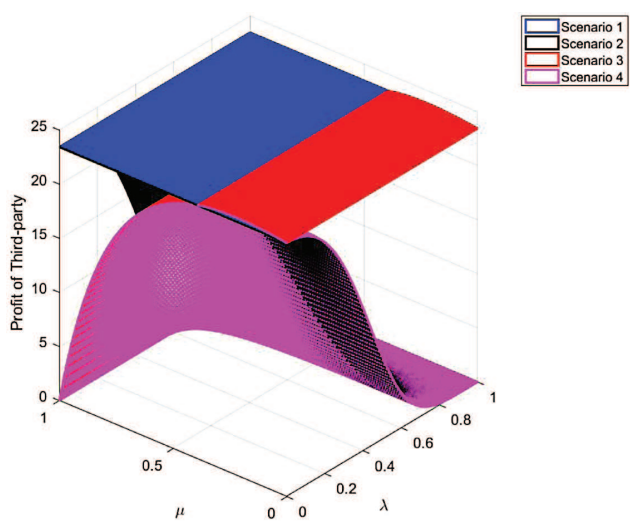

Figure 6 . The impact of $\lambda$ and $\mu$ on $\pi_{t}$. 


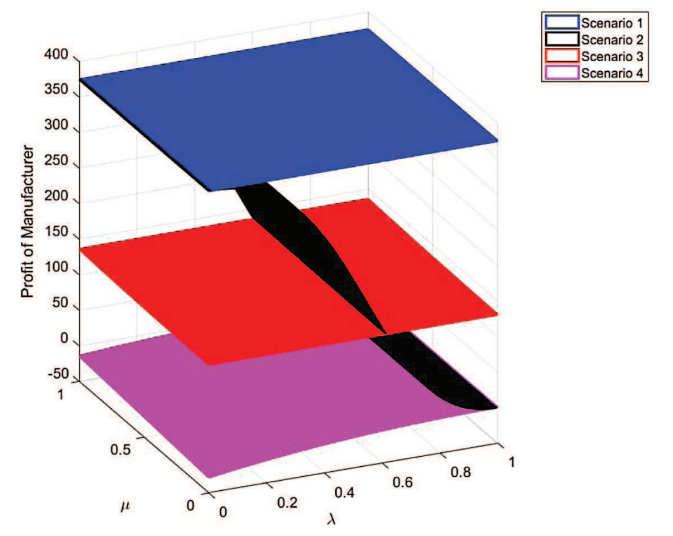

Figure 7 . The impact of $\lambda$ and $\mu$ on $\pi_{m}$.

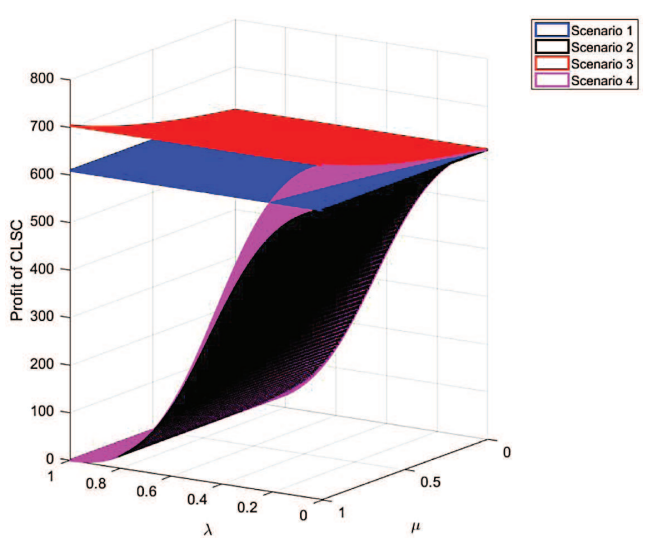

Figure 8. The impact of $\lambda$ and $\mu$ on $\pi_{c}$.

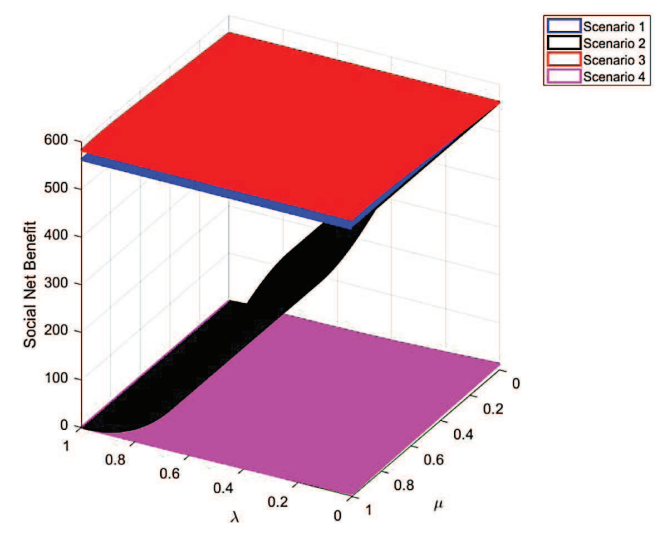

Figure 9. The impact of $\lambda$ and $\mu$ on $S$. 


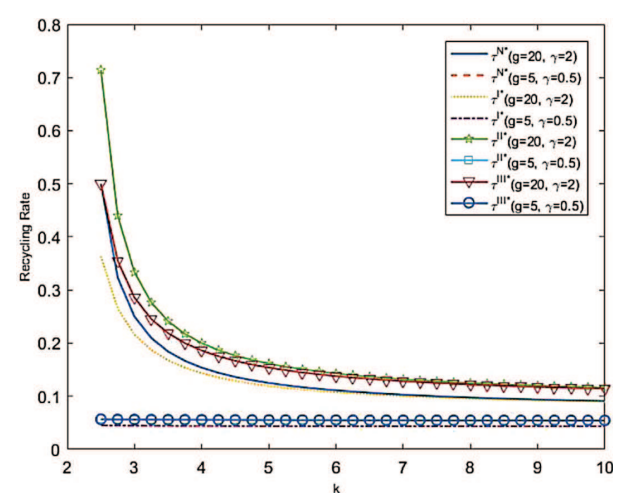

FiguRE 10. The effect of $k$ on $\tau$.

of CLSC in Scenario 3 (II) is optimal among four scenarios, which indicates that sharing recycling investment is able to help the CLSC improve profits. Both sharing service investment and recycling investment are able to optimize the profit of CLSC within a certain range of cost-sharing ratios. Therefore, the implementation of cost-sharing strategies is valuable to the CLSC.

From Figure 9, it is easy to know that the social net benefit in Scenario 2 (I) decreases with the increase of $\lambda$. Similarly, the social net benefit in Scenario 3 (II) increases with the increase of $\mu$. It can also be seen intuitively that the change of social net benefit in Scenario 2 (I) is larger than that in Scenario 3 (II). Under the joint effect of $\lambda$ and $\mu$, the social net benefit in Scenario 4 (III) decreases with the increase of $\lambda$ and $\mu$. From the figure, we can see that the social net benefit in Scenario 3 (II) is optimal among four scenarios, which indicates that sharing the recycling investment is significant and can effectively improve the social net benefit.

\subsection{The effect of $k$ on optimal results}

In this subsection, we assume two numerical cases: (1) $\phi=100, c_{m}=60, c_{r}=30, A=10, \beta=1, C_{L}=$ $1500, \gamma=2, \Delta=30, g=20, \lambda=0.2, \mu=0.4 ;(2) \phi=100, c_{m}=60, c_{r}=30, A=10, \beta=1, C_{L}=1500, \gamma=$ $0.5, \Delta=30, g=5, \lambda=0.2, \mu=0.4$. In Figure 10, compared with the recycling rate in Scenario 1, the recycling rates in Scenarios 3 and 4 is higher. This shows that recycling investment cost-sharing and service and recycling investment cost-sharing can increase the recycling rate. When $k$ is higher, the recycling rate is lower, but it does not have a large impact on the coordination effect of recycling investment cost-sharing and service and recycling investment cost-sharing. The recycling rate in Scenario 2 is always lower than the recycling rate in Scenario 1, which indicates that the sharing of service investment costs by the manufacturer does not help to increase the recycling rate. When $g$ and $\gamma$ are correspondingly changed to one-quarter of the original value, the results do not change. In addition, the recycling rate in the four scenarios always decreases in $k$, that is, high service investment cost will lead to low recycling rate, which is not conducive to the advancement of the product recycling process.

From Figure 11, it can be seen that when $k<4.9$ (case 1), the recycling investment cost-sharing can achieve the third-party profit coordination. On the contrary, this cost-sharing strategy is an inferior measure for the third-party. In the change interval of $k$, both service investment cost-sharing and service and recycling investment cost-sharing strategies are not conducive to third-party's profit. Besides, the third-party's profit in the four scenarios decreases in $k$. In case 2, when $g$ and $\gamma$ are small, no cost-sharing strategies can achieve profit coordination.

Similarly, in case 1, the recycling investment cost-sharing can achieve the coordination of the retailer's profit (see Fig. 12). What is interesting is that the retailer's profit in Scenario 1 and Scenario 3 decrease in $k$, while the retailer's profit in Scenarios 2 and 4 increase first and then decrease in $k$. That is, existing the optimal service 


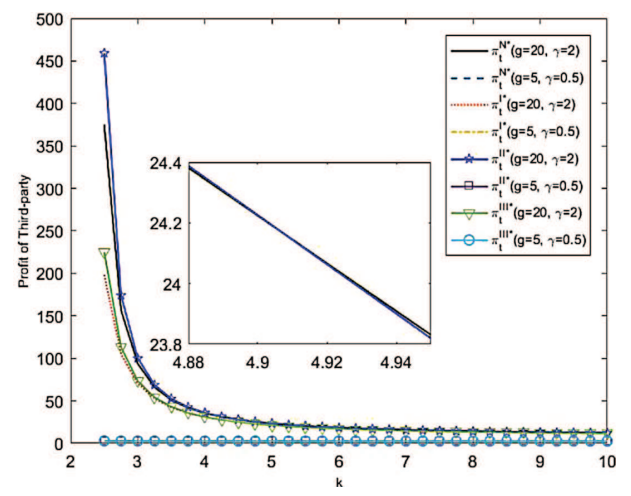

Figure 11. The impact of $k$ on $\pi_{t}$.

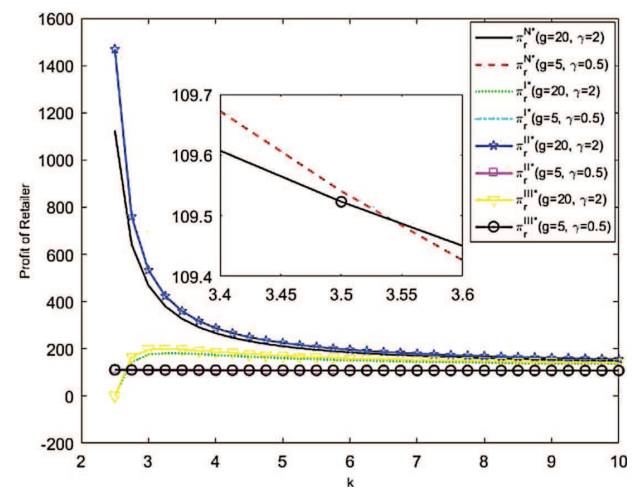

FiguRE 12. The impact of $k$ on $\pi_{r}$.

investment cost coefficient under these two coordination strategies can achieve the improvement of retailer's profit. However, the optimal profit under these two strategies is always lower than the profit without costsharing. In case 2, the recycling investment cost-sharing can still effectively coordinate the retailer's profit. The service and recycling investment cost-sharing can also achieve retailer's profit coordination if and only if $k>3.54$. The service investment cost-sharing still cannot achieve profit coordination.

From Figures 13 and 14, it can also be found that service investment cost-sharing strategy cannot coordinate the manufacturer's profit and the social net benefit. In case 1, the manufacturer's profit and the social net benefit in Scenario 3 are better than that in Scenario 1, which means that recycling investment cost-sharing can improve the profit and social net benefit. The service and recycling investment cost-sharing can also achieve profits coordination if and only if $k>7.5$. In case 2, recycling investment cost-sharing and service and recycling investment cost-sharing can coordinate the manufacturer's profit, which reflects that the decrease of government subsidy and service sensitivity coefficient can enhance the effectiveness of cost-sharing strategies. When $k>3.22$, the social net benefits can be improved by the service and recycling investment cost-sharing strategy. In addition, the service investment cost coefficient has a negative impact on the profit of manufacturer and the social net benefit.

\subsection{The effect of $g$ on optimal results}

Same as Section 5.2, we also assume two numerical cases: (1) $\phi=100, c_{m}=60, c_{r}=30, A=10, \beta=1, C_{L}=$ $1500, \gamma=2, \Delta=30, k=5, \lambda=0.2, \mu=0.4 ;(2) \phi=100, c_{m}=60, c_{r}=30, A=10, \beta=1, C_{L}=1500, \gamma=$ 


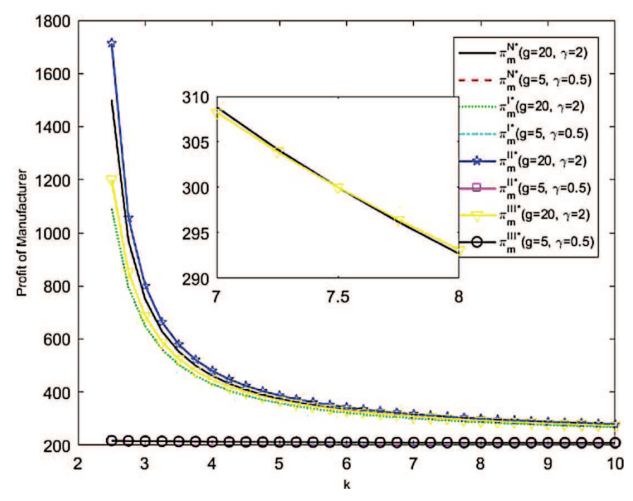

Figure 13. The impact of $k$ on $\pi_{m}$.

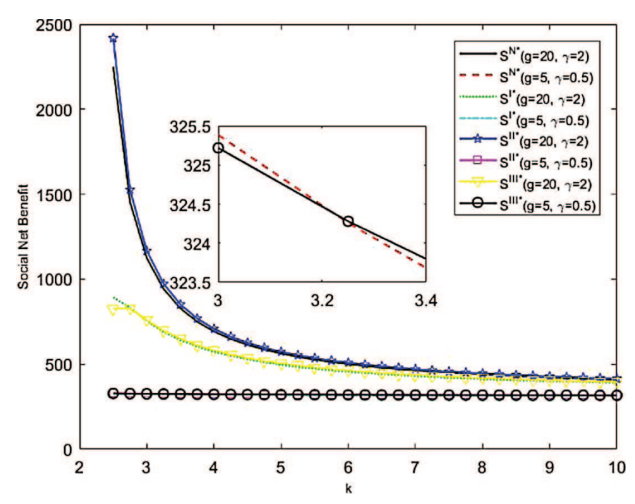

FIGURE 14. The impact of $k$ on $S$.

$0.5, \Delta=30, k=1.25, \lambda=0.2, \mu=0.4$. By analyzing the impact of government subsidy on the recycling rate, it can be seen from the Figures 15-19 that the service investment cost-sharing strategy is an inferior strategy, which means that the strategy is ineffective for improving the recycling rate, profits and social net benefits. In addition to the social net benefits, government subsidy has a positive effect on the recycling rate and profits.

As can be seen from Figure 15, the recycling investment cost-sharing and service and recycling investment costsharing strategies can improve recycling rate in cases 1 and 2. For the third-party's profit (see Fig. 16), in case 1, when $g>20.29$, the recycling investment cost-sharing strategy can achieve coordination. When $g>41.26$, the service and recycling investment cost-sharing strategy can achieve third-party's profit coordination. However, in case 2, if $g>29.34$, the recycling investment cost-sharing strategy can increase third-party's profit. And if $g>34.47$, the service and recycling investment cost-strategy can also improve the profit of third-party. It can be observed from the two cases that when the service cost coefficient and service sensitivity coefficient are small, the effectiveness of the recycling investment cost-sharing is reduced, while the effectiveness of the service and recycling investment cost-sharing strategy is improved. The effectiveness here refers to the scope of the cost-sharing strategy to achieve coordination, which is reflected in the feasible range of government subsidy.

In the two cases of retailer's profit (see Fig. 17), the recycling investment cost-sharing strategy can always achieve profit coordination. In case 1, only when $g>54.17$, the service and recycling investment cost-sharing strategy can play a role in the optimization of the retailer's profit. Similarly, in case 2, the retailer's profit can be coordinated by the service and recycling investment cost-sharing strategy if and only if $g>21.38$. From here we can also observe the same phenomenon, that is, when the service cost coefficient and service 


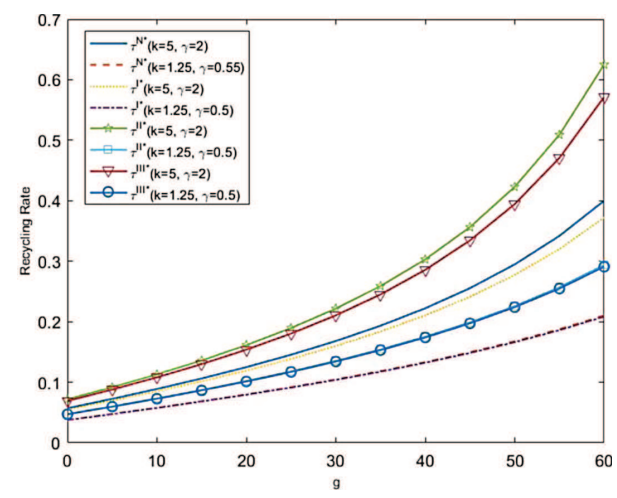

Figure 15. The effect of $g$ on $\tau$.

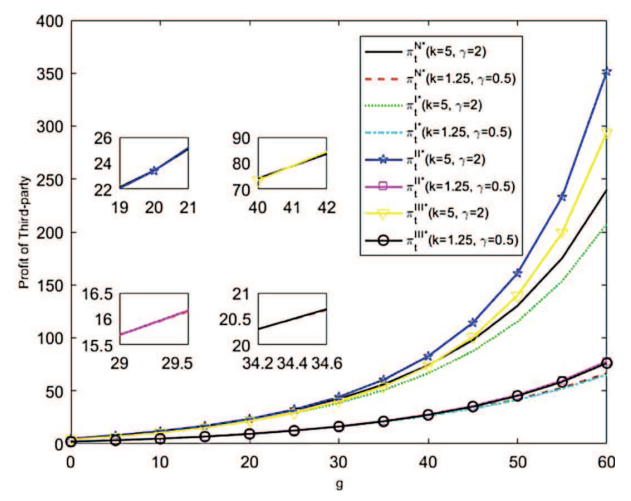

FiguRE 16. The impact of $g$ on $\pi_{t}$.

sensitivity coefficient are small, the effectiveness of the service and recycling investment cost-sharing strategy is improved.

It can be seen from Figure 18 that no matter what kind of case, the recycling investment cost-sharing can achieve coordination. For the service and recycling investment cost-sharing strategy, certain conditions must be met to play a positive role. For example, in case 1, when $g>28.99$, the service and recycling investment cost-sharing strategy can achieve coordination. Similarly, in Case 2, the cost-sharing strategy will only work when $g>4.49$. What needs attention here is that the phenomenon that the effectiveness of cost-sharing strategy is improved still exists.

In Figure 19, it can be observed that only when government subsidy meets certain conditions, the recycling investment cost-sharing strategy can be effective. In case 1, the recycling investment cost-sharing strategy will only play a positive role when $g<45.87$. In case 2 , when $g<53.6$, this strategy can achieve the optimization of social net benefits. It is worth noting that, unlike the above-mentioned profit, the service and recycling investment cost-sharing strategy here does not work. In addition, when the service cost coefficient and service sensitivity coefficient are small, the effectiveness of the recycling investment cost-sharing strategy for thirdparty's profit is weakened, and the effectiveness of recycling investment cost-sharing strategy for the social net benefit is enhanced. 


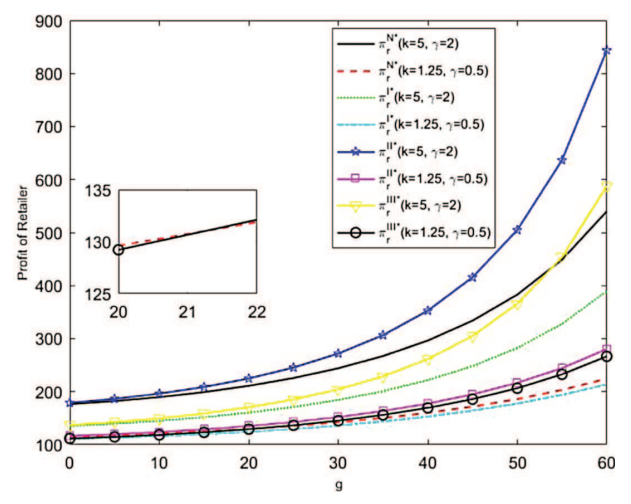

Figure 17. The impact of $g$ on $\pi_{r}$.

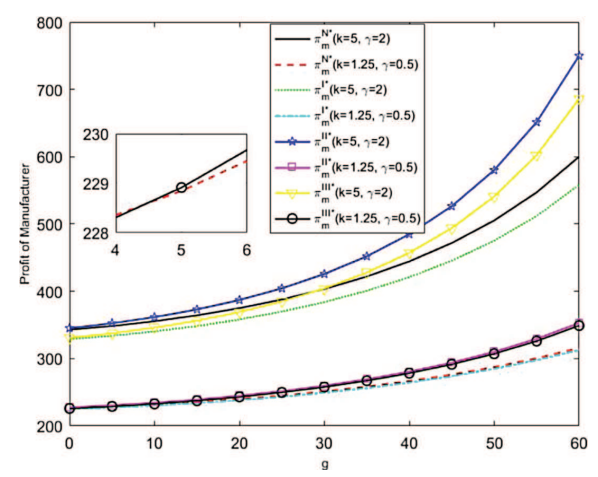

Figure 18. The impact of $g$ on $\pi_{m}$.

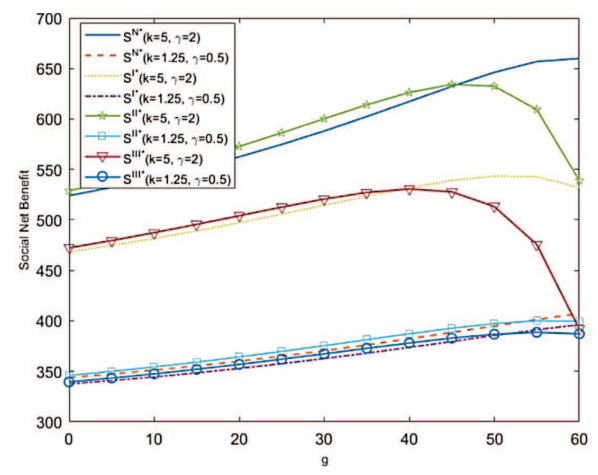

Figure 19. The impact of $g$ on $S$.

\subsection{The effect of $\gamma$ on optimal results}

Here we still assume two numerical cases: (1) $\phi=100, c_{m}=60, c_{r}=30, A=10, \beta=1, C_{L}=1500, k=$ $5, \Delta=30, g=20, \lambda=0.2, \mu=0.4 ;(2) \phi=100, c_{m}=60, c_{r}=30, A=10, \beta=1, C_{L}=1500, k=1.25, \Delta=$ $30, g=5, \lambda=0.2, \mu=0.4$. From Figures 20 to 24 , it can be seen that the service investment cost-sharing strategy under the change of service sensitivity coefficient still cannot achieve the improvement of recycling rate, 


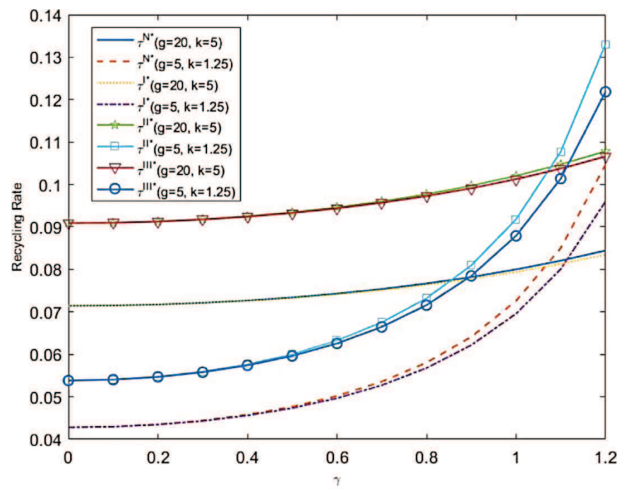

Figure 20. The effect of $\gamma$ on $\tau$.

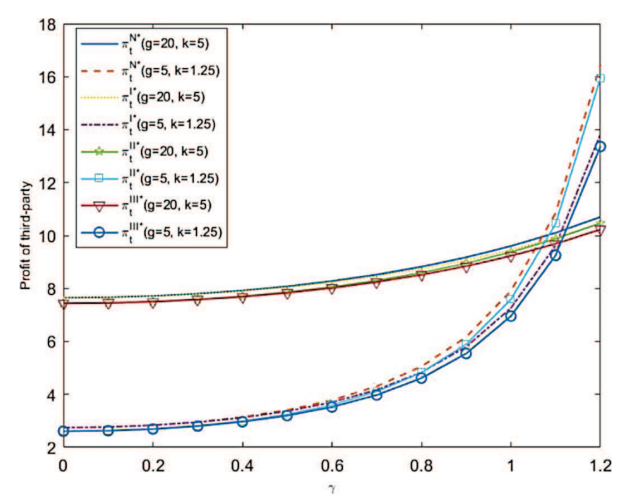

Figure 21. The impact of $\gamma$ on $\pi_{t}$.

profits and social net benefits. However, the recycling investment cost-sharing strategy can effectively optimize the recycling rate, retailer's profit, manufacturer's profit and social net benefit. Besides, in any scenario, the recycling rate, profits, and social net benefits increase as the service sensitivity coefficient increases.

In Figure 20, comparing the recycling rates in cases 1 and 2, when the service cost coefficient and government subsidy are small, as the service sensitivity coefficient increases, the recycling rate in case 2 shows a more obvious upward trend. And when the service sensitivity coefficient is large enough, the recycling rate in case 2 is higher than the recycling rate in case 1 . This shows that under the joint interference of government subsidy and service cost coefficient, even if the government subsidy is not large enough, the recycling rate can be improved.

In the analysis of the impact of the service sensitivity coefficient, it is particularly noteworthy that no matter what kind of case, the three cost-sharing strategies cannot achieve the improvement of third-party profits (see Fig. 21). In addition, comparing the third-party's profit under the three cost-sharing strategies in case 1, the third-party's profit under the service investment cost-sharing strategy are the highest. This implies that compared with the impact of the above-mentioned key parameters, although service investment cost-sharing cannot achieve optimal improvement, it has better stability. In case 2, when $\gamma>0.81$, the third-party's profit under the recycling investment cost-sharing strategy is better than that under the other two strategies. Despite this, there has been the same change as the recycling rate, that is, the third-party's profit when the service cost coefficient and government subsidy are small shows a clear upward trend with changes in service sensitivity. Although the government subsidy is small, but affected by the service cost coefficient, the greater the sensitivity of the service, the higher the profit of the third-party. 


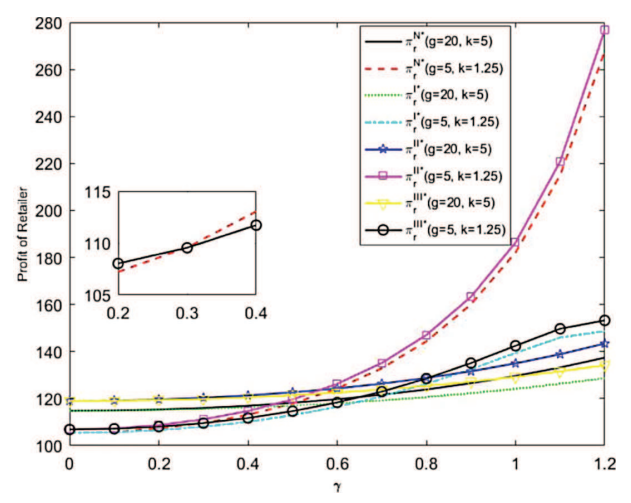

Figure 22. The impact of $\gamma$ on $\pi_{r}$.

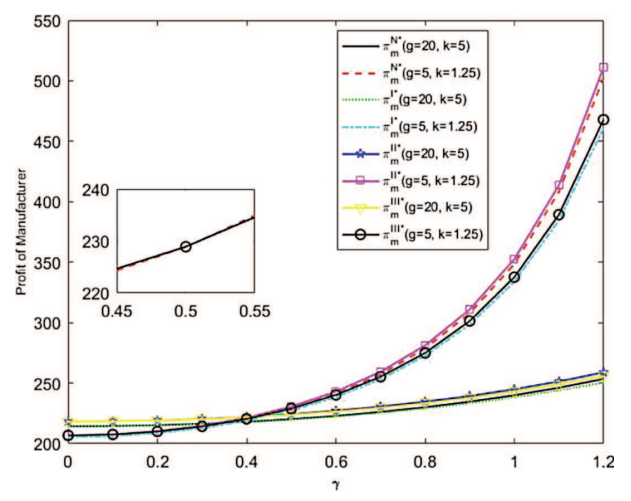

Figure 23. The impact of $\gamma$ on $\pi_{m}$.

From Figure 22, it is easy to observe that the service and recycling investment cost-sharing can achieve the coordination of retailer's profit when $\gamma<0.96$ in case 1 . In case 2 , If $\gamma<0.29$, this strategy can still achieve the improvement of the retailer's profit. This shows that the reduction of government subsidy and service cost coefficient weaken the effectiveness of the service and recycling investment cost-sharing strategy. In addition, when the service sensitivity coefficient is large enough, the retailer's profit under the low government subsidy and low service cost coefficient will be higher.

Similarly, in case 1 (see Fig. 23), the service and recycling investment cost-sharing strategy can achieve an effective improvement in the manufacturer's profit. But in case 2, the service and recycling investment costsharing strategy can achieve profit improvement only when $\gamma<0.51$. This phenomenon can be explained in the same way as the retailer's profit. And, the same as the profit of retailer, when the service sensitivity coefficient exceeds a certain threshold, the profit of manufacturer under low government subsidy and low service cost coefficient will be higher.

The analysis of the relationship between the social net benefit and the service sensitivity coefficient is shown in Figure 24. In case 1 , when $\gamma<0.76$, the cost-sharing strategy can improve the social net benefit, that is, the strategy is effective. In case 2, this strategy can achieve the optimization of social net benefits when $\gamma<0.31$. It is easy to observe that the effective coordination range of this strategy has narrowed, the same phenomenon as the above-mentioned profit has occurred. 


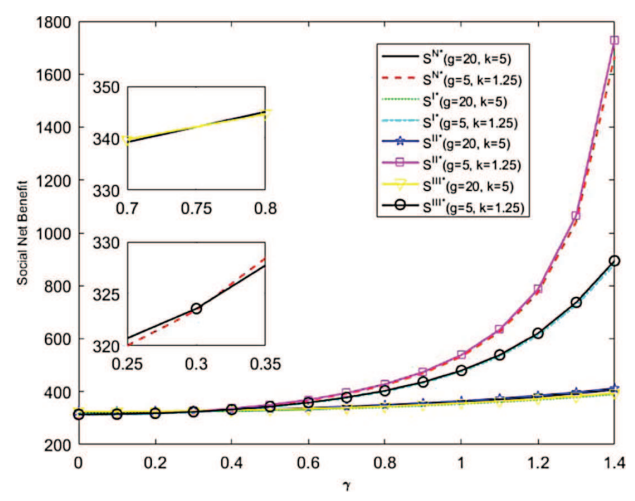

Figure 24. The impact of $\gamma$ on $S$.

\section{Management Insights And CONCLUSIONS}

\subsection{Management insights}

Based on the results of the above numerical analysis, the major findings of this study that managers can use in practice are:

(1) Because the retailer and the recycler need to pay corresponding costs in the sales service and recycling process respectively, this paper proposes three cost-sharing strategies, including service investment costsharing, recycling investment cost-sharing, and service and recycling investment cost-sharing. The results show that the service investment cost-sharing strategy cannot improve the profits of supply chain members. However, the conditions that different decision-makers need to meet are different for the recycling investment cost-sharing and the service and recycling investment cost-sharing strategies. Therefore, in order for a manager to make the optimal decision to maximize his company's profits, he needs to clarify the type of company (such as retailer, manufacturer, or recycler), and then determine the optimal cost-sharing strategy and the favorable conditions of the strategy.

(2) The analysis of the impact of changes in the cost-sharing ratio on decision-making and profit shows that the service investment cost-sharing strategy can effectively increase retail prices and service efforts within effective constraints. However, although this strategy will promote the recycling rate, retailer's profit, thirdparty's profit, manufacturer's profit, and social net benefit, these results have not been effectively improved. Therefore, it is very undesirable for companies to optimize profits and increase recycling rate through this strategy. From the perspective of retail-type enterprises, the recycling investment cost-sharing strategy can completely improve corporate profits, while the service and recycling investment cost-sharing strategy can only play a coordinating role when the proportion of service cost-sharing is low. From the perspective of manufacturing-type enterprises, the profit of manufacturer has not been improved. At this time, it is difficult for the three cost-sharing strategies to achieve a win-win profit among members. From the perspective of recycling-type enterprises, profit improvement can be achieved when the ratio of recycling investment costsharing is less than a certain threshold. At this time, this strategy is the dominant strategy for the enterprise. From a social perspective, compared to other cost-sharing strategies, the recycling investment cost-sharing strategy is a completely dominant strategy.

(3) The analysis of the impact of service cost coefficient changes on decision-making and profit shows that the service cost coefficient has a negative effect on the recycling rate, profits and social net benefits as a whole, that is, the higher the service cost coefficient, the more disadvantageous the profit of all parties. In this case, the service investment cost-sharing strategy is not an optimal strategy, and the recycling investment cost-sharing strategy is an optimal strategy. Therefore, enterprises should avoid the service 
cost-sharing behavior as much as possible, but should tend to choose the recycling investment cost-sharing strategy. Although under certain conditions, the service and recycling investment cost-sharing strategy can achieve the optimization and coordination of decision-making and profit, in terms of strategy comparison, the recycling investment cost-sharing strategy is more dominant. Besides, when government subsidy and service sensitivity coefficient are low, different types of enterprises face changes in different strategic ranges. For example, for recycling-type enterprises, the feasible range of the service and recycling investment costsharing strategy narrows, while for retail-type and manufacturing-type enterprises, the feasible range of this strategy expands. Therefore, for business decision-makers, changes in different factors will have an important impact on their decision-making.

(4) The analysis of the impact of changes in government subsidies on decision-making and profits shows that government recycling subsidy can effectively promote the increase in recycling rate and profits, but for social net benefits, government subsidy is not as large as possible. This is scientifically feasible for policy makers. It will not blindly increase the investment cost of government, and it can also maximize the social net benefit. Moreover, the service investment cost-sharing strategy is still an inferior strategy, and business decisionmakers should avoid it as much as possible. The recycling investment cost-sharing and the service and recycling investment cost-sharing strategies can improve corporate profits. When the service cost coefficient and service sensitivity coefficient is low, the feasible range of these two strategies in optimizing profits becomes wider. Therefore, for decision-makers, the increase in government subsidy and the reduction of service factors can greatly optimize the profits of members.

(5) The analysis of the impact of changes in service sensitivity coefficients on decision-making and profits shows that the service investment cost-sharing strategy is still an inferior strategy for profits and social net benefits. For recycling-type enterprises, any cost-sharing strategies cannot achieve coordination. For other types of enterprises, the recycling investment cost-sharing strategy and the service and recycling investment costsharing strategy can achieve coordination within a certain range. Besides, when government subsidy and service cost coefficient are low, the feasible range of service and recycling investment cost-sharing strategy in optimizing retailer's profit, manufacturer's profit, and social net benefit narrows. It is also worth noting that when government subsidy and service cost coefficient are low, the increase in service sensitivity coefficient can bring more profits to supply chain members, and it can also bring more net benefits to society. Therefore, this largely helps corporate managers to make decisions and choose the best cost-sharing strategy through pre-judgment of service sensitivity coefficients.

\subsection{Conclusion}

This paper studies a closed-loop supply chain that includes a manufacturer, a retailer, and a third-party recycler. In this study, sales service, government recycling subsidy and different cost-sharing strategies were considered to increase the recycling rate, optimize corporate decision-making and improve the profits of supply chain members. The demand in this study is a deterministic model of price and service. Based on a basic decentralized decision-making model, three cost-sharing models are proposed and discussed. This paper uses the Stackelberg game method to obtain the optimal equilibrium results and profits in the four scenarios. Through numerical analysis, the impact of cost-sharing ratio, service cost coefficient, government subsidy and service sensitivity coefficient on profits and social net benefit is also discussed. The results show that in the analysis of the impact of key parameters, the service investment cost-sharing strategy is always an inferior strategy. In most situations, the recycling investment cost-sharing strategy is a dominant strategy, that is, the recycling rate, profits, and social net benefit under this strategy are significantly better. When certain feasible conditions are met, the service and recycling investment cost-sharing strategy can also achieve coordination. Moreover, given other parameter values, the reduction of government subsidy and service sensitivity coefficient will produce different coordination effectiveness for different decision-makers. The reduction of the service cost coefficient and service sensitivity coefficient will increase the effectiveness of the recycling investment cost-sharing and service and recycling investment cost-sharing strategies. The reduction of government subsidy and service cost coefficient will restrict the effectiveness of the service and recycling investment cost-sharing strategy. 
There are also some limitations in our research. Firstly, the market demand we consider is deterministic, but in actual applications, the demand is often uncertain. Therefore, the uncertainty of demand can be considered in future research. Secondly, this paper only focuses on a single sales and single recycling channel. In reality, there are already dual-channel or mixed-channel sales or recycling. This can be further discussed in future studies. Thirdly, this paper mainly considers government subsidies to recyclers. However, the state or country also has policies and regulations on consumer subsidies and remanufacturing subsidies. Therefore, differentiated government subsidies (such as consumer subsidies and remanufacturer subsidies) can be considered in future research. Finally, this paper only investigates the manufacturer Stackelberg game model. In the future, we will explore the vertical Nash game, retailer Stackelberg game, and third-party Stackelberg game models in a closed-loop supply chain, and we believe it will produce more meaningful conclusions and insights.

\section{Appendix A.}

\section{A.1. Proof of Proposition 4.1}

Firstly, we analyze the retailer's decision problem. According to the retailer's profit function, the Hessian matrix of the retailer's profit function $\pi_{R}$ with respect to $p$ and $s$ is $H_{R}^{N}=\left[\begin{array}{cc}-2 \beta & \gamma \\ \gamma & -k\end{array}\right]$, where $\left|H_{R}^{N}\right|=2 \beta k-\gamma^{2}>$ 0 , and leading principal minor of order 1 is $\left|H_{R 1}^{N}\right|=-2 \beta<0$, so the retailer's profit function $\pi_{R}$ is joint concave with respect to $p$ and $s$. The retailer can achieve profit maximization with respect to $p$ and $s$. Combining $\frac{\partial \pi_{R}}{\partial p}=0$ and $\frac{\partial \pi_{R}}{\partial s}=0$, we can get the best response functions of retailer: $\hat{p}=\frac{k(\phi+w \beta)-w \gamma^{2}}{2 \beta k-\gamma^{2}}, \hat{s}=\frac{(\phi-w \beta) \gamma}{2 \beta k-\gamma^{2}}$. Substitute the best response functions into the third-party's profit function, we have $\frac{\mathrm{d}^{2} \pi_{T}}{\mathrm{~d} \tau^{2}}=-2 C_{L}<0$, so the third-party's profit function $\pi_{T}$ is concave with respect to $\tau$. Solving $\frac{\mathrm{d} \pi_{T}}{\mathrm{~d} \tau}=0$, we can get the best response function of third-party: $\hat{\tau}=\frac{(\phi-w \beta) k \beta(b-A+g)}{2\left(2 \beta k-\gamma^{2}\right) C_{L}}$. Substitute the best response functions of retailer and third-party into the manufacturer's profit function, we can derive Hessian matrix of the manufacturer's profit function $\pi_{M}$ with respect to $w$ and $b, H_{M}^{N}=\left[\begin{array}{cc}\frac{k \beta^{2}\left((A-b-g) k \beta^{2}(b-\Delta)+\left(-4 k \beta+2 \gamma^{2}\right) C_{L}\right)}{\left(2 \beta k-\gamma^{2}\right)^{2} C_{L}} & \frac{\beta^{3} k^{2}(A-2 b-g+\Delta)(w \beta-\phi)}{\left(2 \beta k-\gamma^{2}\right)^{2} C_{L}} \\ \frac{\beta^{3} k^{2}(A-2 b-g+2)(w \beta-\phi)}{\left(2 \beta k-\gamma^{2}\right)^{2} C_{L}} & -\frac{k^{2} \beta^{2}(w \beta-\phi)^{2}}{\left(2 \beta k-\gamma^{2}\right)^{2} C_{L}}\end{array}\right]$. Determinant of the Hessian matrix is $\left|H_{M}^{N}\right|=\frac{k^{3} \beta^{4}(w \beta-\phi)^{2}\left(\left(4 k \beta-2 \gamma^{2}\right) C_{L}-k \beta^{2}\left(A^{2}+3 b^{2}+3 b g+g^{2}-3 b \Delta-g \Delta+\Delta^{2}+A(-3 b-2 g+\Delta)\right)\right)}{\left(2 \beta k-\gamma^{2}\right)^{4} C_{L}^{2}}>0$, and leading principal minor of order 1 is $\left|H_{M 1}^{N}\right|=\frac{k \beta^{2}\left((A-b-g) k \beta^{2}(b-\Delta)+\left(-4 k \beta+2 \gamma^{2}\right) C_{L}\right)}{\left(2 \beta k-\gamma^{2}\right)^{2} C_{L}}<0$, so the manufacturer's profit function $\pi_{M}$ is joint concave with respect to $w$ and $b$. Combining $\frac{\partial \pi_{M}}{\partial w}=0$ and $\frac{\partial \pi_{M}}{\partial b}=0$, we can obtain the manufacturer's optimal decisions $w^{N^{*}}, b^{N^{*}}$. Accordingly, we can get the retailer's and third-party's optimal decisions $p^{N^{*}}, s^{N^{*}}, \tau^{N^{*}}$. Further, we can also get the optimal profit of manufacturer, retailer and third-party respectively.

\section{A.2. Proof of Proposition 4.2}

In Scenario 2, firstly we analyze the retailer's optimal decision problem. According to the retailer's profit function, Hessian matrix of the retailer's profit function $\pi_{r}^{I}$ with respect to $p$ and $s$ is, $H_{R}^{I}=\left[\begin{array}{cc}-2 \beta & \gamma \\ \gamma & -(1-\lambda) k\end{array}\right]$. Determinant of the Hessian matrix is $\left|H_{R}^{I}\right|=2 \beta k(1-\lambda)-\gamma^{2}>0$, and leading principal minor of order 1 is $\left|H_{R 1}^{I}\right|=-2 \beta<0$, so the retailer's profit function $\pi_{r}^{I}$ is joint concave with respect to $p$ and $s$. The retailer can achieve profit maximization with respect to $p$ and $s$. Combining $\frac{\partial \pi_{R}^{I}}{\partial p}=0$ and $\frac{\partial \pi_{R}^{I}}{\partial s}=0$, we can get the best response functions of retailer: $\breve{p}=\frac{w \gamma^{2}+k(\phi+w \beta)(-1+\lambda)}{2 \beta k(-1+\lambda)+\gamma^{2}}, \breve{s}=\frac{(w \beta-\phi) \gamma}{2 \beta k(-1+\lambda)+\gamma^{2}}$. Substitute the best response functions into the third-party's profit function, we have $\frac{\mathrm{d}^{2} \pi_{T}^{I}}{\mathrm{~d} \tau^{2}}=-2 C_{L}<0$, so the third-party's profit function $\pi_{t}^{I}$ is concave with respect to $\tau$. Solving $\frac{\mathrm{d} \pi_{T}^{I}}{\mathrm{~d} \tau}=0$, we can get the best response function of thirdparty: $\widetilde{\tau}=\frac{(\phi-w \beta) k \beta(b-A+g)(-1+\lambda)}{2\left(2 \beta k(-1+\lambda)+\gamma^{2}\right) C_{L}}$. Substitute the best response functions of retailer and third-party into the 
manufacturer's profit function, we can derive Hessian matrix of the manufacturer's profit function $\pi_{m}^{I}$ with respect to $w$ and $b, H_{M}^{I}=\left[\begin{array}{ll}A_{1} & B_{1} \\ C_{1} & D_{1}\end{array}\right]$, Where $A_{1}=\frac{k \beta\left((A-b-g) k \beta^{2}(b-\Delta)(1-\lambda)^{2}+2 \beta\left(\gamma^{2}(1-2 \lambda)-2 k \beta(1-\lambda)^{2}\right) C_{L}\right)}{\left(2 \beta k(1-\lambda)-\gamma^{2}\right)^{2} C_{L}}, B_{1}=$ $C_{1}=\frac{\beta^{3} k^{2}(A-2 b-g+\Delta)(w \beta-\phi)(1-\lambda)^{2}}{\left(2 \beta k(1-\lambda)-\gamma^{2}\right)^{2} C_{L}}, D_{1}=-\frac{k^{2} \beta^{2}(w \beta-\phi)^{2}(1-\lambda)^{2}}{\left(2 \beta k(1-\lambda)-\gamma^{2}\right)^{2} C_{L}}$. Determinant of the Hessian matrix is $\left|H_{M}^{I}\right|=$ $A_{1} D_{1}-B_{1} C_{1}>0$, and leading principal minor of order 1 is $\left|H_{M 1}^{I}\right|=A_{1}<0$, so the manufacturer's profit function $\pi_{m}^{I}$ is joint concave with respect to $w$ and $b$. Combining $\frac{\partial \pi_{M}^{I}}{\partial w}=0$ and $\frac{\partial \pi_{M}^{I}}{\partial b}=0$, we can obtain the manufacturer's optimal decisions $w^{I^{*}}, b^{I^{*}}$. Accordingly, we can get the retailer's and third-party's optimal decisions $p^{I^{*}}, s^{I^{*}}$ and $\tau^{I^{*}}$. Further, we can also get the optimal profit of manufacturer, retailer and third-party respectively.

\section{A.3. Proof of Proposition 4.3}

The proof is the same as Propositions 4.1 and 4.2, which is omitted here.

\section{A.4. Proof of Proposition 4.4}

The proof is the same as Propositions 4.1 and 4.2, which is omitted here.

Acknowledgements. This study was partly supported by the National Natural Science Foundation of China (Project Nos. 72042007, 71532007, and 71131006) and Sichuan Science and Technology Program (Project No. 2020JDR0125). The authors would like to thank the anonymous reviewers for their helpful comments and suggestions on improving our study.

\section{REFERENCES}

[1] T. Chakraborty, S.S. Chauhan and M. Ouhimmou, Cost-sharing mechanism for product quality improvement in a supply chain under competition. Int. J. Prod. Econ. 208 (2019) 566-587.

[2] J.M. Chen, W. Zhang and Z.Y. Liu, Joint pricing, services and quality decisions in a dual-channel supply chain. RAIRO:OR 54 (2020) 1041-1056.

[3] A. Chutani and S.P. Sethi, Dynamic cooperative advertising under manufacturer and retailer level competition. Eur. J. Oper. Res. 268 (2018) 635-652.

[4] B. Dan, G. Xu and C. Liu, Pricing policies in a dual-channel supply chain with retail services. Int. J. Prod. Econ. 139 (2012) $312-320$.

[5] A. Dumrongsiri, M. Fan, A. Jain and K. Moinzadeh, A supply chain model with direct and retail channels. Eur. J. Oper. Res. 187 (2008) 691-718.

[6] N. Esmaeili, E. Teimoury and F. Pourmohammadi, A scenario-based optimization model for planning and redesigning the sale and after-sales services closed-loop supply chain. RAIRO:OR 55 (2021) S2859-S2877.

[7] M. Frisk, M. Göthe-Lundgren, K. Jörnsten and M. Rönnqvistab, Cost allocation in collaborative forest transportation. Eur. J. Oper. Res. 205 (2010) 448-458.

[8] D. Ghosh and J. Shah, Supply chain analysis under green sensitive consumer demand and cost sharing contract. Int. J. Prod. Econ. 164 (2015) 319-329.

[9] Y. He, X. Zhao, L.D. Zhao and J. He, Coordinating a supply chain with effort and price dependent stochastic demand. Appl. Math. Model. 33 (2009) 2777-2790.

[10] P. He, Y. He and H. Xu, Channel structure and pricing in a dual channel closed loop supply chain with government subsidy. Int. J. Prod. Econ. 213 (2019) 108-123.

[11] P. He, Y. He, C.M. Shi, H. Xu and L. Zhou, Cost-sharing contract design in a low-carbon service supply chain. Comput. Ind. Eng. 139 (2020) 1-17.

[12] J. Heydari, K. Govindan and A. Jafari, Reverse and closed loop supply chain coordination by considering government role. Transp. Res. Part D: Transp. Environ. 52 (2017) 379-398.

[13] B.Y. Hu and Y. Feng, Optimization and coordination of supply chain with revenue sharing contracts and service requirement under supply and demand uncertainty. Int. J. Prod. Econ. 183 (Part A) (2017) 185-193.

[14] S.K. Jena and S.P. Sarmah, Price and service co-opetition under uncertain demand and condition of used items in a remanufacturing system. Int. J. Prod. Econ. 173 (2016) 1-21.

[15] L. Jiang, Y. Wang and D.M. Liu, Logistics cost sharing in supply chains involving a third-party logistics provider. Cent. Eur. J. Oper. Res. 24 (2016) 207-230.

[16] Y.Q. Jiang, L.P. Liu and A. Lim, Optimal pricing decisions for an omni-channel supply chain with retail service. Int. Trans. Oper. Res. 27 (2020) 2927-2948. 
[17] W. Kerr and C. Ryan, Eco-efficiency gains from remanufacturing: a case study of photocopier remanufacturing at Fuji Xerox Australia. J. Cleaner Prod. 9 (2001) 75-81.

[18] S. Kim, J. Na and B. Kim, Strategic effects of supply chain inventories on sales performance. Eng. Manage. J. 33 (2021) $126-140$.

[19] H. Kurata and S.H. Nam, After-sales service competition in a supply chain: does uncertainty affect the conflict between profit maximization and customer satisfaction? Int. J. Prod. Econ. 144 (2013) 268-280.

[20] G. Li, L. Li and J.S. Sun, Pricing and service effort strategy in a dual-channel supply chain with showrooming effect. Transp. Res. Part E Logistics Transp. Rev. 126 (2019) 32-48.

[21] Z. Li, S. Che, P. Wang, S. Du, Y. Zhao, H. Sun and Y. Li, Implementation and analysis of remanufacturing large-scale asynchronous motor to permanent magnet motor under circular economy conditions. J. Cleaner Prod. 294 (2021) 126233.

[22] D. Littler and D. Melanthiou, Consumer perceptions of risk and uncertainty and the implications for behaviour towards innovative retail services: the case of internet banking. J. Retailing Consum. Serv. 13 (2006) 431-443.

[23] H.H. Liu, M. Lei, H.H. Deng, G.K. Leong and T. Huang, A dual channel, quality-based price competition model for the WEEE recycling market with government subsidy. Omega-Int. J. Manage. Sci. 59 (2016) 290-302.

[24] Y. Liu, B.T. Quan, Q. Xu and J.Y.L. Forrest, Corporate social responsibility and decision analysis in a supply chain through government subsidy. J. Cleaner Prod. 208 (2019) 436-447.

[25] K. Liu, C.X. Wang, L. Liu and L. Xu, Which group should governmental policies target? Effects of incentive policy for remanufacturing industry. RAIRO:OR 55 (2021) 1579-1602.

[26] W.M. Ma, Z. Zhao and H. Ke, Dual-channel closed-loop supply chain with government consumption-subsidy. Eur. J. Oper. Res. 226 (2013) 221-227.

[27] A. Mandal and B. Pal, Effects of green innovation and advertisement in an imperfect production-based competitive supply chain under two-tier credit facility. Math. Methods Appl. Sci. (2021) DOI: 10.1002/mma.7620.

[28] S. Mitra and S. Webster, Competition in remanufacturing and the effects of government subsidies. Int. J. Prod. Econ. 111 (2008) 287-298.

[29] B. Pal and A. Sarkar, Optimal strategies of a dual-channel green supply chain with recycling under retailer promotional effort. RAIRO:OR 55 (2021) 415-431.

[30] B. Pal, L.E. Cardenas-Barron and K.S. Chaudhuri, Price, delivery time, and retail service sensitive dual-channel supply chain. Sci. Iran. 28 (2021) 1765-1779.

[31] S. Panda, N.M. Modak and L.E. Crdenas-Barrn, Coordinating a socially responsible closed-loop supply chain with product recycling. Int. J. Prod. Econ. 188 (2017) 11-21.

[32] G. Raz and A. Ovchinnikov, Coordinating pricing and supply of public interest goods using government rebates and subsidies. IEEE Trans. Eng. Manage. 62 (2015) 65-79.

[33] A. Sarkar and B. Pal, Competitive pricing strategies of multi-channel supply chain under direct servicing by the manufacturer. RAIRO:OR 55 (2021) S1849-S1873.

[34] A. Sarkar and B. Pal, Pricing and service strategies in a dual-channel supply chain under return-refund policy. Int. J. Syst. Sci.-Oper. Logistics (2021) DOI: 10.1080/23302674.2021.1884769.

[35] R.C. Savaskan, S. Bhattacharya and L.N. Van Wassenhove, Closed-loop supply chain models with product remanufacturing. Manage. Sci. 50 (2004) 239-252.

[36] P.J. Schneider and S. Zielke, Price versus service: can retailers beat showrooming with competence? J. Retailing Consum. Serv. 61 (2021) 102592.

[37] J.B. Sheu, Bargaining framework for competitive green supply chains under governmental financial intervention. Transp. Res. Part E Logistics Transp. Rev. 47 (2011) 573-592.

[38] R. Subramanian, M. Ferguson and T.L. Beril, Remanufacturing and the component commonality decision. Prod. Oper. Manage. 22 (2013) 36-53.

[39] E. Sundin and B. Bras, Making functional sales environmentally and economically beneficial through product remanufacturing. J. Cleaner Prod. 13 (2005) 913-925.

[40] A.A. Taleizadeh, S.T.A. Niaki and N. Alizadeh-Basban, Cost-sharing contract in a closed-loop supply chain considering carbon abatement, quality improvement effort, and pricing strategy. RAIRO:OR 55 (2021) S2181-S2219.

[41] T.A. Taylor, Supply chain coordination under channel rebates with sales effort effects. Manage. Sci. 48 (2002) $992-1007$.

[42] W. Wang and Q. Da, Study on premium and penalty mechanisms for the electronic product reverse supply chain considering the leading of government. Chin. J. Manage. Sci. 18 (2010) 62-67.

[43] K. Wang, Y.M. Wei and Z. Huang, Potential gains from carbon emissions trading in China: a DEA based estimation on abatement cost savings. Omega-Int. J. Manage. Sci. 63 (2016) 48-59.

[44] Z. Wang, J.Z. Huo and Y.R. Duan, Impact of government subsidies on pricing strategies in reverse supply chains of waste electrical and electronic equipment. Waste Manage. 95 (2019) 440-449.

[45] Y.Y. Wang, R.J. Fan, L. Shen and W. Miller, Recycling decisions of low-carbon e-commerce closed-loop supply chain under government subsidy mechanism and altruistic preference. J. Cleaner Prod. 259 (2020) 1-13.

[46] D. Wu, J.H. Chen, P. Li and R.J. Zhang, Contract coordination of dual channel reverse supply chain considering service level. J. Cleaner Prod. 260 (2020) 1-13.

[47] X.Y. Wu, Z.P. Fan and B.B. Cao, Cost-sharing strategy for carbon emission reduction and sales effort: a nash game with government subsidy. J. Ind. Manage. Optim. 16 (2020) 1999-2027. 
[48] T. Xiao and D. Yang, Price and service competition of supply chains with risk-averse retailers under demand uncertainty. Int. J. Prod. Econ. 114 (2008) 187-200.

[49] S. Xie and C. Bai, New rules on disposal of waste electrical and electronic products. Lexology (November 30) (2010) http: //www. lexology. com/library/detail. aspx?g=6e6da831-c189-4c81-82d4-3f6b45b3105b.

[50] L. Xie and J.H. Ma, Study the complexity and control of the recycling-supply chain of China's color TVs market based on the government subsidy. Commun. Nonlinear Sci. Numer. Simul. 38 (2016) 102-116.

[51] J. Xie, W. Zhang, L. Liang, Y. Xia, J. Yin and G. Yang, The revenue and cost sharing contract of pricing and servicing policies in a dual-channel closed-loop supply chain. J. Cleaner Prod. 191 (2018) 361-383.

[52] L. Xu, C.X. Wang, Z. Miao and J.H. Chen, Governmental subsidy policies and supply chain decisions with carbon emission limit and consumer's environmental awareness. RAIRO:OR $\mathbf{5 3}$ (2019) 1675-1689.

[53] R.L. Yan and Z. Pei, Retail services and firm profit in a dual-channel market. J. Retailing Consum. Serv. 16 (2009) 306-314.

[54] F. Yang, F. Shan and M. Jin, Capacity investment under cost sharing contracts. Int. J. Prod. Econ. 191 (2017) $278-285$.

[55] D. Yao and J.J. Liu, Competitive pricing of mixed retail and e-tail distribution channels. Omega-Int. J. Manage. Sci. 33 (2005) 235-247.

[56] P. Zhang, C.C. Lee and Y.Q. Wu, The impact of government subsidies and retailer contracts on product recovery. Asia-Pac. J. Oper. Res. (2021) 2040023. DOI: 10.1142/S0217595920400230.

[57] X.M. Zhang, Q.W. Li, Z. Liu and C.T. Chang, Optimal pricing and remanufacturing mode in a closed-loop supply chain of WEEE under government fund policy. Comput. Ind. Eng. 151 (2021) 106951.

[58] J.H. Zhao, D.L. Zeng, L.P. Che, T.W. Zhou and J.Y. Hua, Research on the profit change of new energy vehicle closed-loop supply chain members based on government subsidies. Environ. Technol. Innov. 19 (2020) 1-19.

[59] Y.W. Zhou, J.S. Guo and W.H. Zhou, Pricing/service strategies for a dual-channel supply chain with free riding and service-cost sharing. Int. J. Prod. Econ. 196 (2018) 198-210.

\section{Subscribe to Open (S20) A fair and sustainable open access model}

This journal is currently published in open access under a Subscribe-to-Open model (S2O). S2O is a transformative model that aims to move subscription journals to open access. Open access is the free, immediate, online availability of research articles combined with the rights to use these articles fully in the digital environment. We are thankful to our subscribers and sponsors for making it possible to publish this journal in open access, free of charge for authors.

\section{Please help to maintain this journal in open access!}

Check that your library subscribes to the journal, or make a personal donation to the S2O programme, by contacting subscribers@edpsciences.org

More information, including a list of sponsors and a financial transparency report, available at: https://www. edpsciences.org/en/maths-s2o-programme 